\title{
An Integrated Approach to Software Process Improvement at Wipro Technologies: veloci-Q
}

\author{
V. Subramanyam \\ Sambuddha Deb \\ Priya Krishnaswamy \\ Rituparna Ghosh
}

March 2004

TECHNICAL REPORT

CMU/SEI-2004-TR-006

ESC-TR-2004-006 



\section{An Integrated Approach to Software Process Improvement at Wipro Technologies: veloci- $Q$}

CMU/SEI-2004-TR-006

ESC-TR-2004-006

V. Subramanyam Sambuddha Deb

Priya Krishnaswamy

Rituparna Ghosh

March 2004

Wipro Technologies 
The Software Engineering Institute is a federally funded research and development center sponsored by the U.S. Department of Defense.

Copyright 2004 Carnegie Mellon University.

NO WARRANTY

THIS CARNEGIE MELLON UNIVERSITY AND SOFTWARE ENGINEERING INSTITUTE MATERIAL IS FURNISHED ON AN “AS-IS” BASIS. CARNEGIE MELLON UNIVERSITY MAKES NO WARRANTIES OF ANY KIND, EITHER EXPRESSED OR IMPLIED, AS TO ANY MATTER INCLUDING, BUT NOT LIMITED TO, WARRANTY OF FITNESS FOR PURPOSE OR MERCHANTABILITY, EXCLUSIVITY, OR RESULTS OBTAINED FROM USE OF THE MATERIAL. CARNEGIE MELLON UNIVERSITY DOES NOT MAKE ANY WARRANTY OF ANY KIND WITH RESPECT TO FREEDOM FROM PATENT, TRADEMARK, OR COPYRIGHT INFRINGEMENT.

Use of any trademarks in this report is not intended in any way to infringe on the rights of the trademark holder.

Internal use. Permission to reproduce this document and to prepare derivative works from this document for internal use is granted, provided the copyright and "No Warranty" statements are included with all reproductions and derivative works.

External use. Requests for permission to reproduce this document or prepare derivative works of this document for external and commercial use should be addressed to the SEI Licensing Agent.

This work was created in the performance of Federal Government Contract Number F19628-00-C-0003 with Carnegie Mellon University for the operation of the Software Engineering Institute, a federally funded research and development center. The Government of the United States has a royalty-free government-purpose license to use, duplicate, or disclose the work, in whole or in part and in any manner, and to have or permit others to do so, for government purposes pursuant to the copyright license under the clause at 252.227-7013.

For information about purchasing paper copies of SEI reports, please visit the publications portion of our Web site (http://www.sei.cmu.edu/publications/pubweb.html). 


\section{Table of Contents}

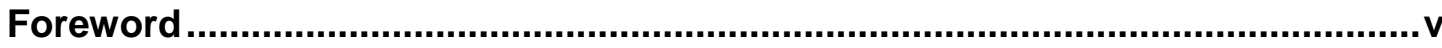

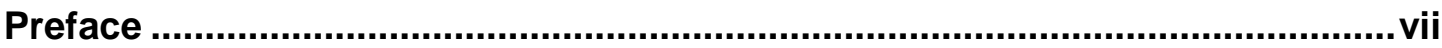

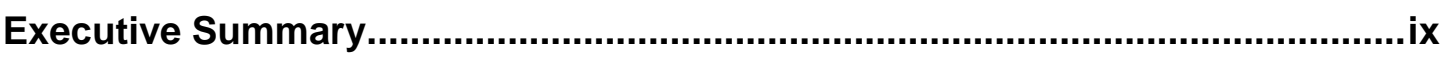

Abstract

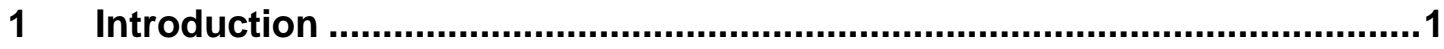

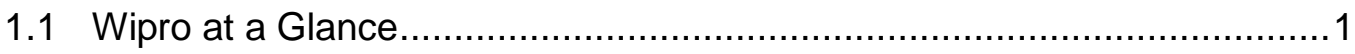

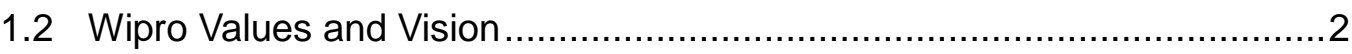

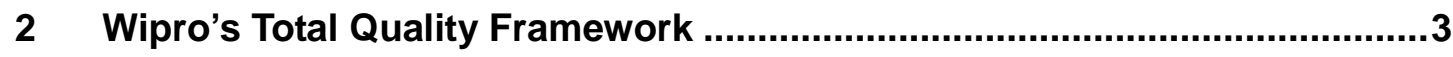

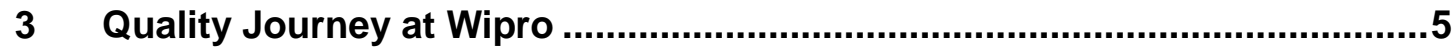

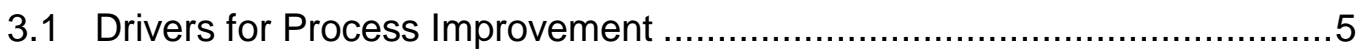

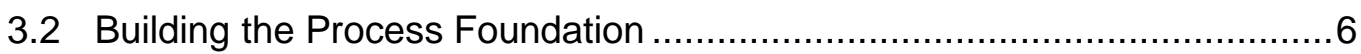

3.3 The Process Improvement Paradigm ................................................. 7

3.4 Continuous Process Optimization.....................................................

3.5 The Common Process Initiative .......................................................... 11

3.6 Improving People Processes ............................................................. 14

3.7 Integrating Software, Systems, and Products ...................................... 14

3.8 Information Security ...................................................................... 16

$4 \quad$ Implementation of the Total Quality Framework.......................................19

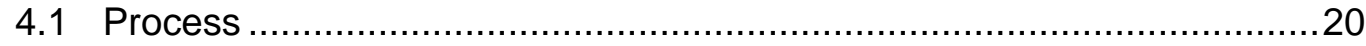

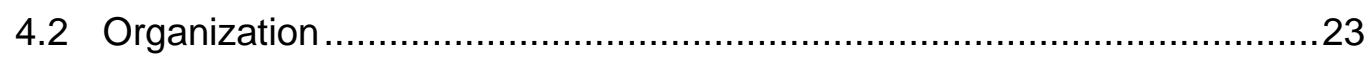

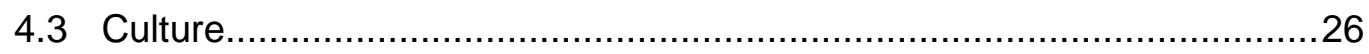

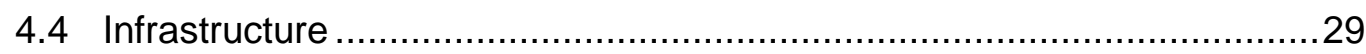

4.4.1 Integrated Process Automation ................................................29

4.4.2 Project Data Bank ……………............................................. 30

4.4.3 Audit Management............................................................ 31

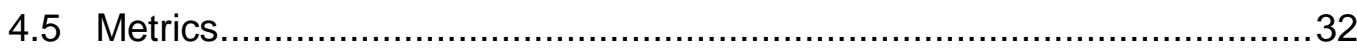

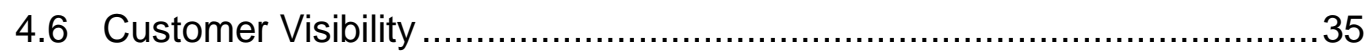




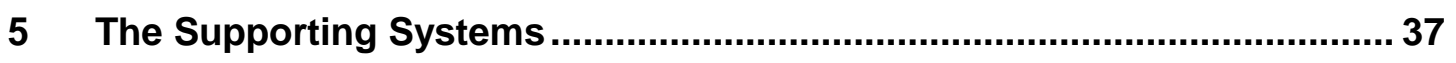

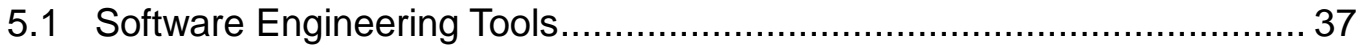

5.2 IT Management....................................................................... 38

5.3 Human Resources and Competency Framework ................................ 38

5.4 Knowledge Management Systems ................................................. 39

5.5 Talent Transformation..................................................................... 40

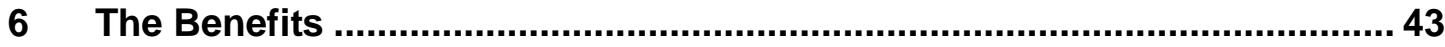

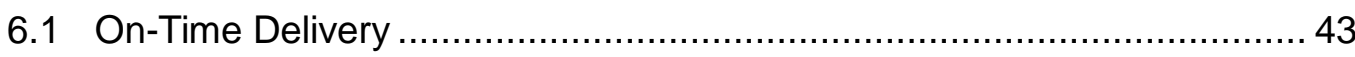

6.2 Improved Quality .................................................................. 43

6.3 For the Customers ........................................................................ 45

6.4 Improvement Results .......................................................... 46

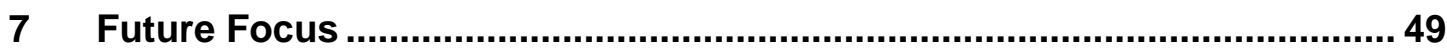

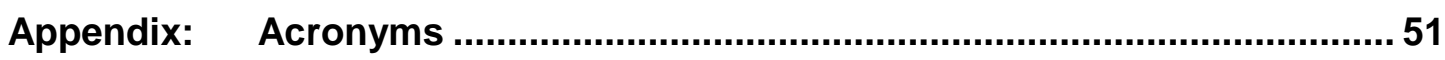

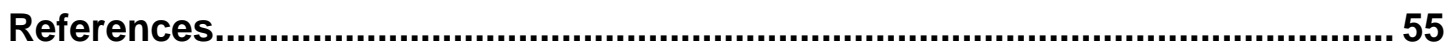




\section{List of Figures}

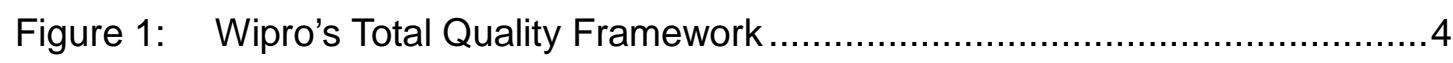

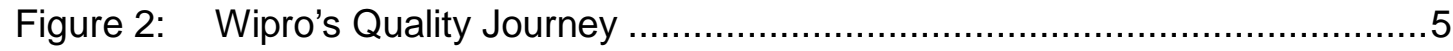

Figure 3: Six Sigma Integrated with ISO and CMM ................................... 10

Figure 4: $\quad$ Unified Quality System .......................................................... 13

Figure 5: Information Security Management System (ISMS) ............................16

Figure 6: Implementation of Total Quality Framework ..................................19

Figure 7: Six Sigma in Project Execution................................................. 21

Figure 8: The Project Execution Perspective ................................................22

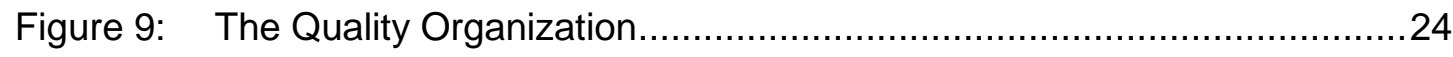

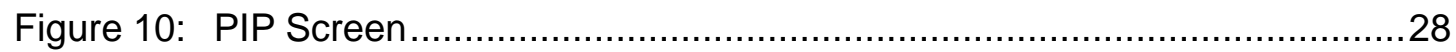

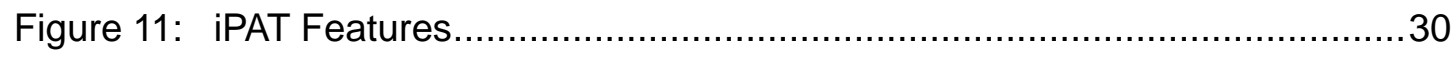

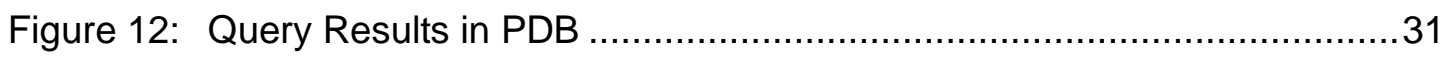

Figure 13: Parameters in Productivity Performance Models .................................33

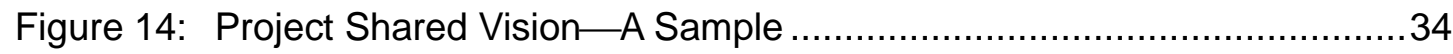

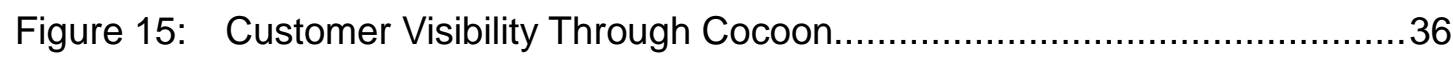

Figure 16: Tools Used During a Typical SDLC................................................

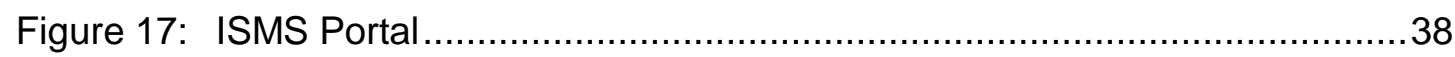

Figure 18: People Capability Maturity Model ................................................. 39

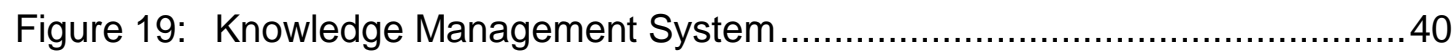




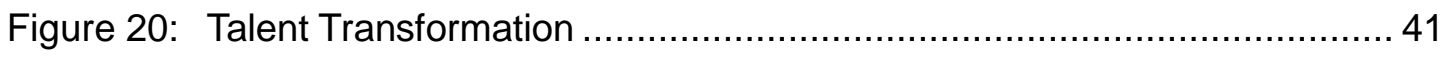

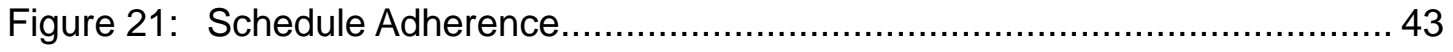

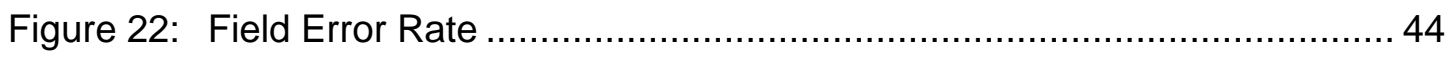

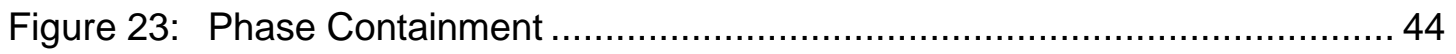

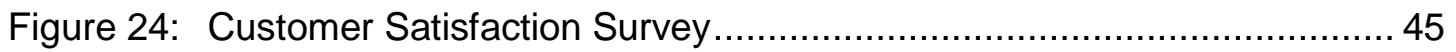




\section{Foreword}

The Software Process Achievement (SPA) Award was jointly established by the Carnegie Mellon ${ }^{\circledR}$ Software Engineering Institute $\left(\mathrm{SEI}^{\mathrm{SM}}\right)$ and the Institute of Electrical and Electronics Engineers (IEEE) Computer Society in 1994 to recognize individual or team excellence in improving an organization's software processes. The award's criteria are as follows:

- Significant: The improvements must have a demonstrated impact on the organization's software capability.

- Sustained: The improvements must have resulted in a broad, documented improvement program that will have a positive impact on the organization's future projects.

- Measured: The improvements must be supported by data clearly demonstrating improved software capability to date as well as a plan to use data to guide future improvements.

- Impacting: The improvements must be shared throughout the organization, as well as with the community at large, to amplify their impact.

Between 1994 and 2003, five outstanding teams have received an award. For further information on the award and its recipients, visit <http://www.sei.cmu.edu/managing/ieee-award/> .

The SPA Award Committee (Vic Basili, Barry Boehm, Watts Humphrey, Manny Lehman, and Bill Riddle) selected the Software Process Engineering Group (SEPG) at Wipro Technologies, Bangalore, India, as a 2003 awardee to recognize the truly exceptional breadth and depth of both their work and the support for continuing improvement they have established. The major observations that led to our decision were as follows:

Wipro Technologies maintained steady progress though frequent periods of change, often quite widespread. With every change, Wipro Technologies found a way to leverage it to the benefit of its software process improvement efforts.

In slightly more than 10 years, Wipro Technologies achieved International Standards Organization (ISO) 9001 certification and Capability Maturity Model ${ }^{\circledR}\left(\mathrm{CMM}^{\circledR}\right)$, People Capability Maturity Model (P-CMM) and Capability Maturity Model Integration (CMMI ${ }^{\circledR}$ ) Maturity Level 5 certification throughout its 10,000 person, international workforce. During this period, they also successfully addressed the criteria established by other standards, for example, Telecom 9000 (TL 9000) and British Standard 7799 (BS 7799).

Wipro Technologies has continuously gathered quality and productivity data since the inception of its software process improvement program in the mid-1990s. These data have been consistently and extensively used to guide Wipro Technologies' improvement activities and 
support its software development projects. To bolster the impact of its measurement activities, Wipro Technologies has included data-oriented Six Sigma activities in its improvement program for the past three-to-four years.

Wipro Technologies has created a large, 15-to-20 person, SEPG staffed by people with a wide range of abilities and skills including, for example, statistical analysis and graphical design. This group creates assets (templates, guidance documents, etc.) to help projects operate at high levels of software process capability. It also provides mentoring-style support to help projects appropriately and consistently apply these assets. In addition, the group establishes procedures for promoting (and rewarding) "grass roots" suggestions for improving the assets and sharing experiences in using them. Finally, the SEPG is actively investigating the development of new models and measures for achieving higher degrees of quality and productivity.

Much of the support for access to, application of, and improvement to the assets is provided by a well-designed and well-maintained Web site deployed through the organization's intranet. This Web site supports widespread sharing of "best practices" as well as "lessons learned" throughout the organization. Other mechanisms (for example, an annual companywide technical forum) are also used to broaden the impact.

Wipro Technologies actively participates in a benchmarking activity sponsored by the Software Process Improvement Network (SPIN) in Bangalore's large software community. Through this participation, Wipro Technologies has not only helped other organizations establish software process improvement programs but also identified target capability levels and improvement activities for Wipro Technologies' own program.

The Award Committee felt that these aspects of Wipro Technologies' software process improvement activities clearly demonstrate excellence. In addition, we were especially impressed by the fact that Wipro Technologies has viewed each and every accomplishment not as an "ends" — as a stopping point— but rather as a "means"—as establishing a basis for moving on to even more significant and broader improvements.

The Award Committee feels that Wipro Technologies' achievements establish a "best of class" benchmark against which other organizations should calibrate and evaluate their software process improvement efforts. An organization's efforts will, obviously, depend on their business goals, workforce capabilities, and marketplace influences. But this report on Wipro Technologies' "improvement journey" identifies not only the basic concerns that organizations should consider but also a coherent set of actions organizations could take, over time, to scope and continuously improve their software process improvement programs.

William E. Riddle

Chair, Award Committee

Software Process Achievement Award 


\section{Preface}

In the early 1980s, Wipro, then a vegetable oil company, diversified into the information technology (IT) sector. With liberalization hitting India in the 1990s, Wipro broadened its sphere of operations and entered the global arena, with IT service operations handled by two divisions, Wipro Global Research and Development (R\&D) and Wipro Enterprise Solutions.

As time progressed, Wipro widened its service range; organizational changes were inevitable, the workforce increased rapidly, and operations were spread across multiple geographies. At each stage of growth, specific challenges arose that demanded focused improvements. Entry into the international market posed specific challenges of on-time, on-cost deliveries aligned with emerging technology and dynamic customer needs. Given its ambitious goals and vision, Wipro was convinced that systematic process improvement was needed in order to be "best in class," internationally.

Wipro's quality improvement journey commenced with basic process definition using frameworks like those defined by the International Standards Organization (ISO). However, rapid growth in the scale and range of Wipro's operations increased the need for mature quality processes. The focus was on process capability, people capability, defect reduction, and productivity improvement. Wipro's relentless pursuit of process excellence bears testimony to the fact that Wipro was one of the earliest software services companies to be assessed at Maturity Level 5 of the Carnegie Mellon ${ }^{\circledR}$ Software Engineering Institute $\left(\mathrm{SEI}^{\mathrm{SM}}\right.$ ) Capability Maturity Model $^{\circledR}\left(\mathrm{CMM}^{\circledR}\right)$, People Capability Maturity Model (P-CMM), and Capability Maturity Model Integration $\left(\mathrm{CMMI}^{\circledR}\right)(\mathrm{V} 1.1)$ frameworks. Wipro was also one of the earliest software services companies to adopt Six Sigma.

Wipro's quality system has come a long way in terms of catering to the diverse challenges and growing demands of the international market. The evolution has been steady and significant-from volumes of printed manuals to a single, Web-based, integrated system available at each practitioner's desktop. The focus on a total quality approach - through innovation in process, people, products, and services - coupled with technology enabled the evolution of veloci-Q: fast track to quality, Wipro's holistic enterprise-wide quality system. veloci-Q embodies the best practices of each process improvement initiative and integrates multiple quality processes to deliver measurable business benefits.

SM SEI is a service mark of Carnegie Mellon University.

๑ Capability Maturity Model, CMM, and CMMI are registered in the U.S. Patent and Trademark Office by Carnegie Mellon University. 
Wipro's goal of sustaining quality leadership became a stimulus for continuous process enhancement. Towards this, the Institute of Electrical and Electronics Engineers (IEEE) Computer Society Software Process Achievement (SPA) Award forms an important milestone in Wipro's continuous journey of process capability, knowledge sharing, and service to the industry.

This report provides a brief history of Wipro's quality journey. It describes the strategy, evolution, and organization-wide deployment of Wipro's process improvement model. This report also elaborates Wipro's pioneering approach to integrating the key elements of an organization-wide process improvement initiative-Process, Product and People. 


\section{Executive Summary}

Wipro has a holistic approach to quality management, with quality initiatives being driven through business-aligned measures. At Wipro, quality has always been viewed from the perspective of the customer, leading to a total quality approach that integrates people and process. Wipro's total quality framework is optimized simultaneously along five interrelated dimensions of process, organization, culture, infrastructure, and metrics. During all of Wipro's quality initiatives, all five dimensions have been optimized simultaneously, though incrementally.

Processes are aligned with industry best practices and internationally renowned standards and frameworks like International Standards Organization (ISO) 9001, Capability Maturity Model (CMM), People Capability Maturity Model (P-CMM), and Six Sigma methodologies, amongst others. Wipro understands the spirit of such models, maps its relevance to the organization's process improvement goals, and rigorously implements these goals to achieve its business needs. At Wipro, quality is everyone's responsibility, with ownership and accountability prevalent at every level in the organization. The total quality approach has systems in place to ensure the capture and dissemination of invaluable knowledge. Continuous focus and investment are made through the enhancement of tools and infrastructure to support process improvement initiatives. These process improvement initiatives are ably supported by an independent quality function, with the objective of defining, maintaining, and improving quality processes. Several supporting systems supplement the overall process, creating an organizational environment for integration.

Throughout Wipro's quality journey, changing business needs and organizational goals brought about challenges that concerned merging multiple frameworks, retaining flexibility, educating and engaging personnel, keeping the overheads low, and infusing vitality, while maintaining continuity. Wipro was convinced that systematic and continuous process improvement was the answer to prevalent challenges.

Wipro commenced its quality journey by establishing ISO 9001-certified basic processes, moving on to laying a foundation for process improvement with CMM Maturity Level 5. Six Sigma concepts and methodologies were integrated to ensure continuous optimization in key process areas. Doing this also brought about a focused customer-centric and data-driven paradigm to product and process quality. P-CMM Maturity Level 5 established processes to address critical people-process issues successfully and improve the maturity of workforce practices. Achieving 
Capability Maturity Model Integration (CMMI) Maturity Level 5 enabled the development of a broad base of processes relating to systems engineering, software engineering, and integrated product development. Wipro introduced international benchmark standards on information security when it aligned with the British Standard 7799 (BS 7799), with a focus on the confidentiality, integrity, and availability of information.

veloci-Q, Wipro's enterprise-wide quality system, integrates multiple quality processes to deliver measurable benefits to both the business and customers. veloci-Q is continuously enhanced in a structured manner with a conscious integration of people and project execution processes.

Because quality is customer driven, the emphasis has continuously been on integrating and implementing approaches through a simultaneous focus on defect reduction, timeliness, and productivity. This emphasis has translated to lower maintenance costs, schedule-overrun costs, and development costs for customers. Measurements and progress indicators have been oriented towards what the customer deems important and what the customer pays for. Towards this, Six Sigma concepts have played an important role in

- improving performance through a precise quantitative understanding of the customer's requirements

- eliminating defects from existing processes, products, and services

- improving the effectiveness in upstream processes of the software development life cycle

In summary, Wipro's holistic approach to quality management is centered on a single, flexible, and customizable quality system - veloci-Q. Quality has always been viewed from the customer's point of view, and this forms the basis for all quality initiatives and improvements. Industry standard frameworks, which cover the entire organization, have been rigorously implemented and practiced after determining the best frameworks for the situation. Quality enjoys a broad ownership at Wipro, with quality goals being aligned to business objectives and performance. The focus on an organization-wide, data-driven approach to process improvement has led to the institutionalization of a strong metrics program. In all, Wipro's minimalist but rigorous approach to quality management is equipped with a strong feedback loop for continuous improvement of the system. 


\section{Abstract}

This report captures the details of Wipro's quality journey through continuous process improvement. This journey towards excellence has led to the prestigious Institute of Electrical and Electronics Engineers (IEEE) Computer Society Award for Software Process Achievement in 2003. This award is for achieving high software process capability and establishing a basis for moving to a broad improvement program that concerns people and products, rather than just the processes.

This report details the process improvement activities and the evolution of processes and systems over a period of time. Wipro's integrated approach to quality-veloci-Q—is detailed with an emphasis on the process improvement initiatives, supporting technology, and people capability that bring positive business results and enable Wipro to meet its customers' everincreasing demands. The challenges and benefits accrued from Wipro's total quality approach are outlined, including the quantitative results of measuring the impact of Wipro's process improvement model. 


\section{Introduction}

Transforming a 1.4 million dollar vegetable oil company to one of the world's first software services companies to attain Software Engineering Institute (SEI) Capability Maturity Model (CMM) Maturity Level 5 for software quality and People Capability Maturity Model (P$\mathrm{CMM}$ ) Maturity Level 5 for people processes requires a strong commitment from senior management, zeal to innovate and excel from the workforce, and a viable business model, but above all it requires a strong quality system that blends processes with technology to steer the company through its long journey to the top.

\subsection{Wipro at a Glance}

Wipro Limited started in 1947, when Western India Vegetable Products Limited was incorporated in Maharashtra, India. The vegetable products factory gradually expanded into a consumer products group and then entered the information technology (IT) area. Wipro consists of several divisions. Wipro Technologies is the global technology services division offering a full portfolio of services across industries. Wipro also has a profitable presence in niche market segments of consumer products and lighting.

Wipro Technologies provides comprehensive IT solutions and services, including system integration, information systems outsourcing, package implementation, software application development and maintenance, IT infrastructure outsourcing, product design services, business process outsourcing, and research and development services to around 300 global corporations. Wipro Technologies provides services to industry verticals (such as finance, insurance, manufacturing, health care, retail, logistics, travel, media, publishing, energy, and utilities) and to leading technology equipment companies across the globe.

Wipro's American Depository Receipts (ADRs) are listed on the New York Stock Exchange, and its equity shares are listed in India on the Mumbai Stock Exchange and the National Stock Exchange, among others. 


\subsection{Wipro Values and Vision}

One of the key philosophies driving Wipro's business has been its values. Apart from capturing the essence of beliefs existing in the organization, these values have enabled the organization to be more customer driven.

Wipro's values are embodied in its promise statement: With utmost respect to human values, we promise to serve our customers with integrity, through innovative, value-for-money solutions, by applying thought, day after day.

The functioning of the organization is based on the values and beliefs, which are considered fundamental and non-negotiable in the functioning of the company. The promise statement is propagated throughout and adopted by every company and division operating under the Wipro umbrella.

These values help Wipro fulfill its business vision of being one of the top global brands as well as being one of the "best in class" with respect to leadership in business, customers, and people. 


\section{Wipro's Total Quality Framework}

Wipro has a holistic approach to quality management. This approach embodies a conscious integration of people and processes as shown in Figure 1. At Wipro, quality has always been customer oriented. The emphasis has continuously been on integrating and implementing approaches through a simultaneous focus on defect reduction, timeliness, and productivity improvement. Measurements and progress indicators have been oriented towards what the customers deem important and what they pay for. Wipro has always been on the forefront in terms of investing in tools and methodologies that enable it to deliver cost advantages and productivity improvements continuously for the benefit of customers.

Wipro aligns with industry best practices and internationally renowned standards/frameworks like International Standards Organization (ISO) 9001, CMM, P-CMM, Six Sigma methodologies, and Telecom 9000 (TL 9000) standard, among others. Wipro understands the spirit of such models, maps its relevance to the organization's process goals, and rigorously implements these goals based on applicability. veloci-Q, Wipro's enterprise-wide quality system, integrates multiple quality processes and is continuously enhanced in a structured manner.

A strong emphasis upon building a professional work environment, leaders from within, and having a global outlook for business and growth have led to innovation of people processes on a continued basis. Over the years, Wipro has significantly strengthened its competencybased people processes and demonstrated innovative practices in talent acquisition, deployment, and development, based on strategic needs.

With the growing importance on aligning business operations with customer needs and driving continuous improvement, Six Sigma concepts have been closely integrated into the project execution methodology. Integrating Six Sigma concepts was also intended to bring rigor in effective upstream processes of the software development life cycle. Implementation of Six Sigma methodologies brought in quantitative understanding, cost savings, and performance improvement towards product quality.

In summary, at Wipro, process, people and technology are integrated to enable the effective implementation of IT strategies and solutions, which can be customized to individual customer needs and delivered with consistency and reliability. 


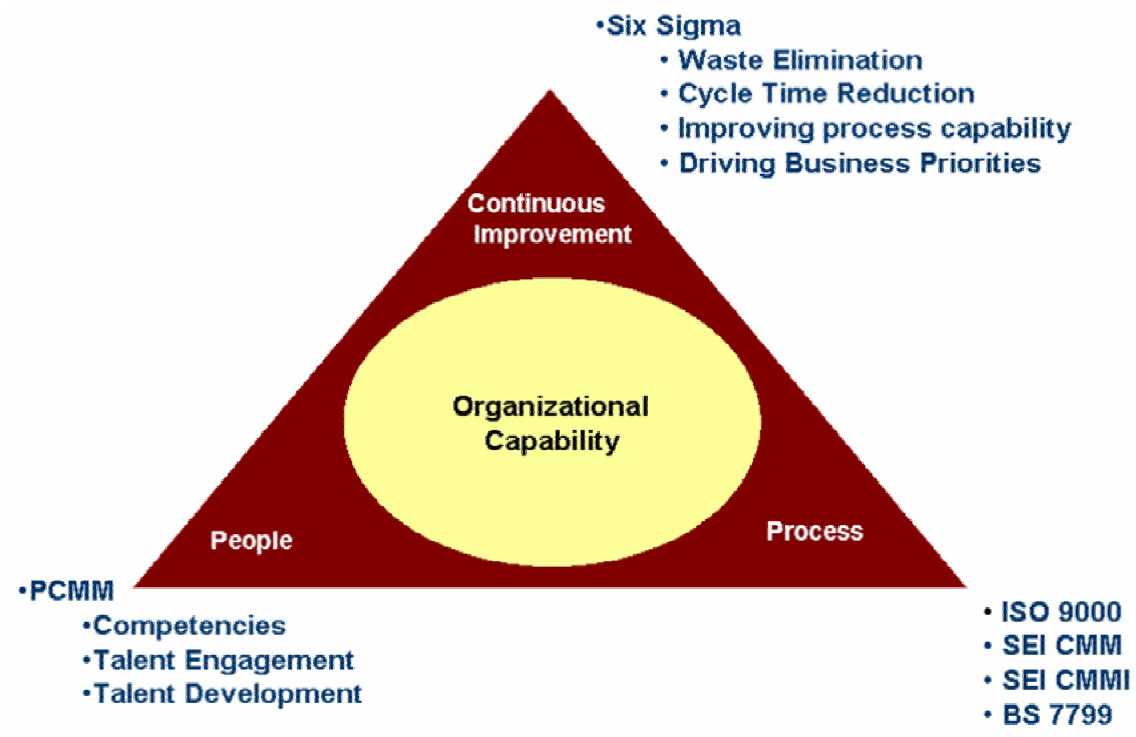

Figure 1: Wipro's Total Quality Framework 


\section{Quality Journey at Wipro}

Given the ambitious goals of the organization and its vision, it was imperative that business processes be improved to meet the changing market requirements. It was with this realization that Wipro embarked on the quality journey in 1991-92. In the past decade, we have crossed several of the journey's milestones. Today in Wipro, quality is like integrity-nonnegotiable. We pursue quality with missionary zeal and have put in place robust processes to ensure that we deliver quality with Six Sigma consistency. veloci-Q, our holistic, enterprisewide quality approach integrates multiple quality processes to deliver measurable business benefits.

Figure 2 depicts the key milestones in Wipro's quality journey.

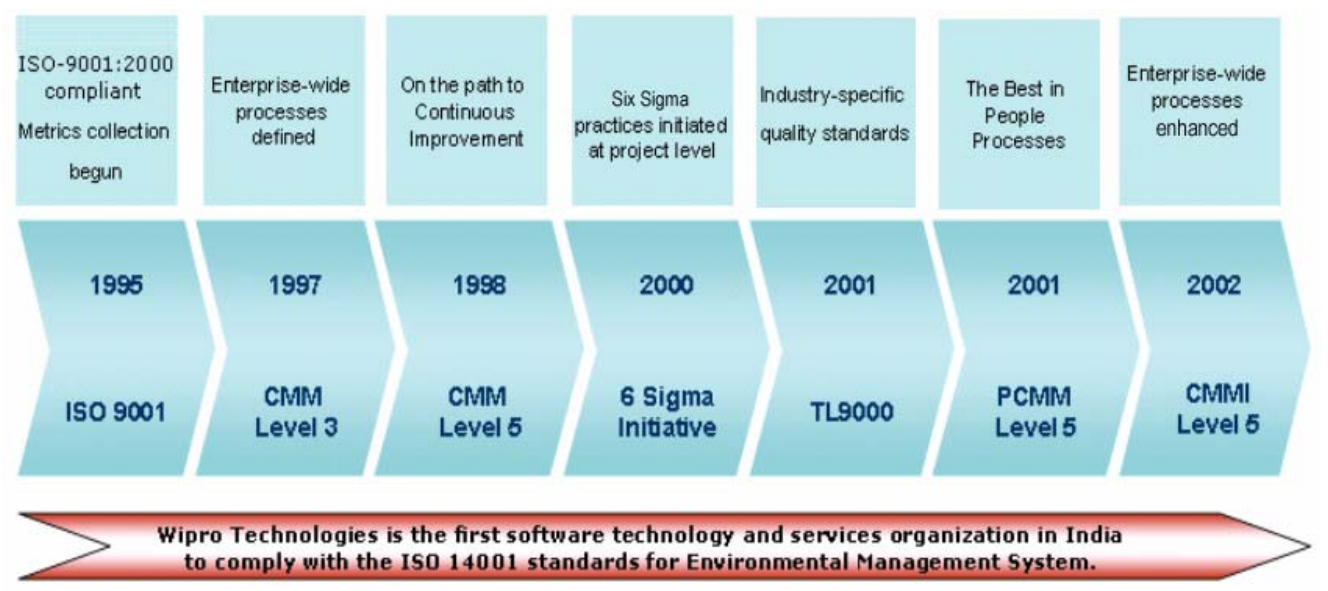

Figure 2: Wipro's Quality Journey

\subsection{Drivers for Process Improvement}

When established, Wipro Technologies' IT services operation was under two divisions: Wipro Enterprise Solutions and Wipro Global Research and Development (R \& D). Both divisions separately initiated their formal quality journeys in 1991-92.

The business vision to excel in the global arena led to Wipro's focus on process improvement. Observations of Wipro's projects revealed the following: 
- Software development was people dependent, leading to inconsistencies in the absence of a strong process.

- Every project was different, leading to inconsistencies in output.

- Projects had high maintenance costs.

- High customer expectations demanded more features, good documentation, and easy maintenance.

- Software quality could not be attained overnight but had to evolve over time.

This situation precipitated a need for improved quality by applying various quality models, as early as 1992 .

\subsection{Building the Process Foundation}

Initially, there was a need to establish basic processes. The quality framework adopted to address this was ISO 9001 [ISO 00]. While there were other frameworks available, the organization chose ISO 9001 for the following reasons:

- ISO 9001 was a general framework and could be applied to any type of business.

- It helped in addressing basic processes.

- It helped in meeting requirements for export to the European market.

- The ISO framework brought in a rigor for processes through regular audits.

The ISO 9001 implementation involved the following:

- training employees on the ISO 9001 framework

- forming an initial quality team and management representative

- forming task teams to write processes

- reviewing processes with the help of task teams

- implementing the framework in different locations

- conducting internal audits to verify compliance

ISO 9001 certification was obtained in January 1995. Wipro has successfully undergone several surveillance and re-certification audits since then. The current quality system meets the requirements of the newly released ISO 9001:2000 standard. 
The outcome of this initiative was the establishment of a structure for the quality function and the development of an organizational level Quality Management System (QMS). Apart from this, regular quality review meetings, life-cycle model definitions, and periodic compliance audits were institutionalized.

Key benefits of implementing the ISO 9001 framework were as follows:

- Formal software engineering techniques were put in place.

- Wipro was able to address varying needs of customers with software development life cycle (SDLC) models.

- A metrics program was instituted across the organization to track key data.

- Process control points were established that helped to establish a disciplined way of executing projects systematically.

- Above all, ISO 9001 helped to institutionalize various processes across the organization and led to increased rigor during project execution.

\subsection{The Process Improvement Paradigm}

Growing business needs presented new challenges because the ISO 9001 framework was too generic. While ISO 9001 enabled Wipro to lay the basic foundation for documenting systems and bringing about process rigor, a framework that could prescribe processes for specific software engineering practices was required, with a focus on process improvement. A quantitative process management system was required that would enable the smooth induction of new and rapidly evolving technologies.

Embodying the principles of Total Quality Management (TQM), the SEI's Capability Maturity Model describes key practices critical for success in software development [Paulk 93], which was most suitable for us at that point in time. The SEI-CMM framework

- enabled systematic and step-wise process improvement (from Maturity Level 2 to Maturity Level 5)

- enabled the building of an organization database, based on best practices and estimates

- advocated the use of metrics that were based on business needs

- advocated effective risk management strategies

- enabled defect prevention activities at various levels

- advocated the effective use of software engineering methodologies and tools

- facilitated tailoring of processes depending on project and business requirements 
In 1995, a core group was identified to study and gain an understanding of the CMM framework. The following activities were carried out:

- performing a gap analysis of the existing quality system with respect to the CMM

- conducting a process survey with practitioners, focusing not only on the CMM, but also on benefits and issues related to existing processes

- developing solutions for identified barriers and improvement areas

Gaps were identified with respect to the CMM framework. These were in areas such as estimation, risk management, change management, metrics identification, collection and analysis, intergroup coordination, and training. Task teams, which consisted of practitioners and quality group members, were constituted to implement the framework. Some of the key activities during this phase of the process improvement initiative were the following:

- enhancing procedures, guidelines, templates, and checklists for requirements management, project planning, and software configuration management

- establishing estimation procedures, risk management practices, and a metrics program

- introducing Project Performance Analysis (PPA) to make project teams appreciate the value of metrics

- creating an independent quality assurance team (Process QA) and a central Software Engineering Process Group (SEPG).

- defining roles, responsibilities, and objectives for all groups

- using the ISO 9001 audit mechanism to formalize team meetings across the organization

- institutionalizing process-related training across the organization and setting up a separate training group

- establishing a comprehensive Web-based quality system

Wipro Enterprise Solutions was certified to be compliant with SEI-CMM Maturity Level 5 in December 1998, and Wipro Global R\&D was certified to be compliant with Maturity Level 5 in June 1999.

The outcome of this initiative was a well-defined quality system with a common set of processes for project execution and suitable tailoring guidelines. Review and inspection processes were institutionalized across projects. Quality Improvement Councils (QICs) and Management Review Meetings (MRMs) were constituted to share best practices and address issues. A strong metrics program was introduced as part of the continuous improvement paradigm of CMM, which involved metrics collection and analysis at multiple levels. Monitoring of project metrics data, defect prevention activities, and risks was also institutionalized. 
The other benefits realized as a result of CMM were as follows:

- $\quad$ significant reduction of defects

- quantified, robust processes to manage offshore customer projects with improvement in schedule adherence

- effective use of software engineering methodologies and tools to improve productivity and quality

- effective risk management

- $\quad$ project monitoring and control with well-defined metrics

- $\quad$ structured change control processes

\subsection{Continuous Process Optimization}

By the late 1990s, all businesses were operating in a truly global environment, and Wipro was no exception. Our competitors were large international players and the demands for product quality and operational excellence increased considerably. Previous standards were no longer sufficient. To survive in a highly competitive scenario where the customer had more choices than before, Wipro had to raise the bar for quality leadership within the organization.

While ISO 9001 and the SEI-CMM helped in the definition and institutionalization of processes, a methodology was still needed to enable higher levels of optimization, directly resulting in lower costs and increased customer satisfaction. Six Sigma methodologies were identified not only to address these challenges but also to aid in sustaining the process improvement for which the CMM laid the foundation. In fact, Six Sigma directly contributes to Maturity Level 5 - continuous optimization of key process areas. Six Sigma achieves dramatic improvement in business performance through a precise understanding of customer requirements and the elimination of defects from existing processes, products, and services. Wipro decided to raise the quality bar in all key process areas to Six Sigma level. Six Sigma was adopted as a management philosophy to encompass every sphere of work-from a secretary's desk to the Chairman's office.

Wipro chose to implement Six Sigma because Six Sigma

- focused on the customer and was based on data

- integrated well with Wipro's other quality initiatives

- was measurable, unlike other quality systems

- was an effective approach for removing defects from products and services 
- was project based and provided immediate milestones

- gave us a competitive edge

The journey to Six Sigma started in 1997. Interim milestones were defined, and goals were set for reaching Six Sigma in identified critical business processes across the corporation. Institutionalizing Six Sigma required both specific and common measures, which involved the following:

- Six Sigma organization

- launch of the Mission Quality department in 1997 as an umbrella covering all approaches to Six Sigma, to facilitate the Six Sigma initiative across the corporation

- $\quad$ surround methodologies

- asset utilization (tools usage, server utilization)

- transaction areas (maintenance productivity, ticket turnaround, error-free information service operations)

- $\quad$ project methodologies

- defect reduction through Transactional Quality Using Six Sigma (TQSS); Define, Measure, Analyze, Improve, Control (DMAIC); Developing Six Sigma Software (DSSS); and Designing for Customer Satisfaction and Manufacturability (DCAM)

- cycle-time reduction through TQSS and Cross-Functional Process Mapping (CFPM)

- tools

- statistical tools (normal distribution, $\mathrm{Z}$ distribution, etc.)

- non-statistical tools (Voice of Customer table, Failure Mode Effect Analysis [FMEA], Quality Function Deployment, etc.)

Figure 3 depicts the way Six Sigma is seamlessly integrated with ISO and CMM.

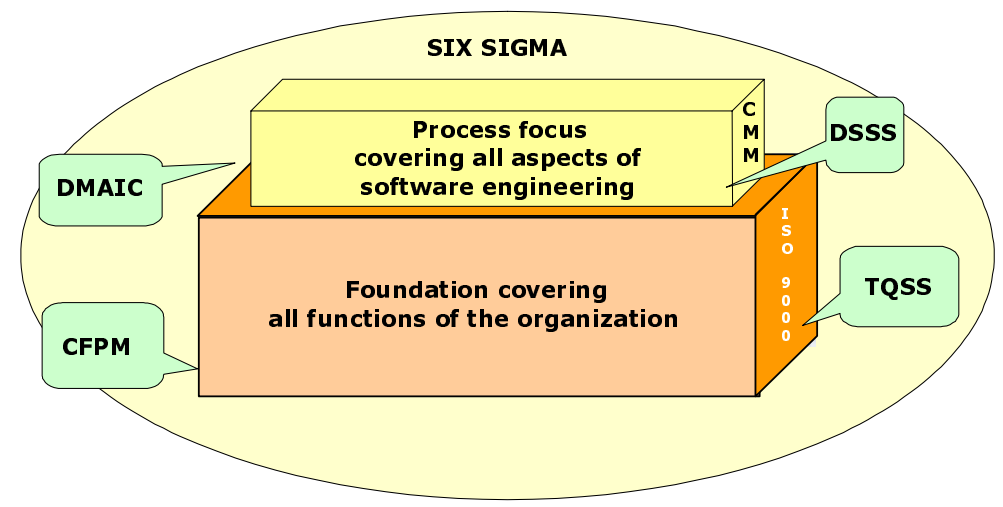

Figure 3: Six Sigma Integrated with ISO and CMM 
When the Six Sigma program was launched in 1997, quality was made the first objective of every senior level manager. By 2000, Wipro identified critical business processes, 70 Black Belts were trained, and quality objectives percolated down to middle management. Wipro developed Six Sigma methodologies to meet specific requirements of transactional processes, software design, and development processes and to improve existing processes using the rigor of statistical tools and techniques. Wipro also launched its own Six Sigma methodology called Developing Six Sigma Software.

As opposed to traditional methods of software development, the application of DSSS methodology built a tighter integration of the customer requirements (called Voice of Customer) to the technical requirements (called Voice of Engineer) and the control that needs to be exercised on both of these using statistical techniques (called Voice of Process). The initial part of the DSSS process focuses on developing the user requirements correctly, and the latter part focuses on rigorous design and implementation using a variety of tools from a toolkit.

By 2001, Wipro developed more problem domain-specific methodologies aligned to the nature of business and projects, 150 Black Belts were trained, and more than 500 projects were conducted. The projects predominantly addressed transactional areas such as sales process, billing accuracy, internal management information system (MIS) accuracy, and software engineering/design. The Six Sigma Engagement Effectiveness Index (SEE Index) was also institutionalized across the organization. By 2002, we attained the maturity phase where statistical rigor was taken to a new level.

The main benefits that Wipro derived from the Six Sigma drive were as follows:

- improved customer satisfaction measured through an annual customer satisfaction (CSAT) survey

- significant improvement in the performance of software products developed for customers through application of Wipro's DSSS methodology based on project-specific needs

- reduction in the field errors in software projects

- $\quad$ significant decrease in installation failures in the hardware business

- significant year-on-year financial savings through reduced rework and reduced cycle time

- increase in cost benefits translated to customers

\subsection{The Common Process Initiative}

Both of Wipro's IT service divisions had established strong software engineering processes for project execution through the development of their Web-based quality systems called Quality Management System (QMS) and Quality System Manual (QSM). Organizational restructuring took place in 1999. As a part of the restructuring, the two divisions were inte- 
grated into Wipro Technologies (WT), and the business units were aligned with domains of operations. Project teams working in similar areas were merged, and new business units were created based on the area of operations.

Project execution with two quality systems created confusion in daily operations. Since both were well established and were delivering results, selecting one over the other would have created management and cultural issues. Over the years, the quality systems had grown considerably in size and were fairly prescriptive in nature.

Wipro felt a need to evolve a "new," simple yet flexible quality system, which was intended to bring about standardization and uniformity across all Wipro's projects in terms of

- terminology used in projects

- roles and responsibilities

- collection and interpretation of data and metrics

- integration of the best practices of both QMS and QSM

- seamless integration of Six Sigma concepts into project execution methodology to drive continuous improvement

This initiative began in June 2000, with task teams being formed to evolve the new system. The following key activities were performed:

- Study and analyses

This included the structure of the existing systems, including project life-cycle models, project engineering, project management methodologies, and roles and responsibilities. The Web sites and training modules were also analyzed.

- Strategy validation and input gathering

Preview sessions were conducted across the organization to validate the unified approach suggested by the task teams. The inputs from the preview sessions were systematically analyzed for incorporation into the new system. Processes were drafted and assets were developed. These were again reviewed by practitioners across the organization and were fine-tuned. Policies and procedures were reviewed for adequacy and compliance to standards by external certifying agencies.

- Awareness building

The quality system was christened veloci-Q: fast track to quality, chosen through an organization-wide contest to name the system. Awareness about the new quality system was built within the organization through poster campaigns, quizzes, and frequently asked questions (FAQs). Practitioners were kept up to date on development of the new quality system through regular status updates in quality forums and through broadcast mails. 


\section{- Deployment and training}

Deployment plans for existing projects and new projects were worked out with clear transition activities. Detailed training courses were conducted for quality group members. Orientation sessions and role-based training were also conducted across the organization to facilitate easy transition.

The result (shown in Figure 4) was a new integrated approach, veloci-Q, which achieved the overall objective of having a quality system that enabled delivery of quality products and services without slowing down the system. A combination of the best of both QMS and QSM, veloci-Q removed outdated information and duplications that had accumulated over time. Introduction of Six Sigma concepts increased the customer and business focus of project execution processes. veloci-Q complies with the coveted Capability Maturity Model Integration for Systems Engineering, Software Engineering, and Integrated Product and Process Development (CMMI-SE/SW/IPPD), V1.1 and ISO 9001:2000 frameworks.

The Web-based system has a simple and intuitive "look-and-feel." Ease of navigation is enabled by quick access to process artifacts, each just a mouse-click away. Access to different sections of the quality system is enabled by pop-up menus, with rich text format/Excel (RTF/XLS) downloads provided for templates and checklists. veloci-Q is equipped with a powerful navigator, to provide categorized roadmaps, based on roles, activities, and life-cycle models.

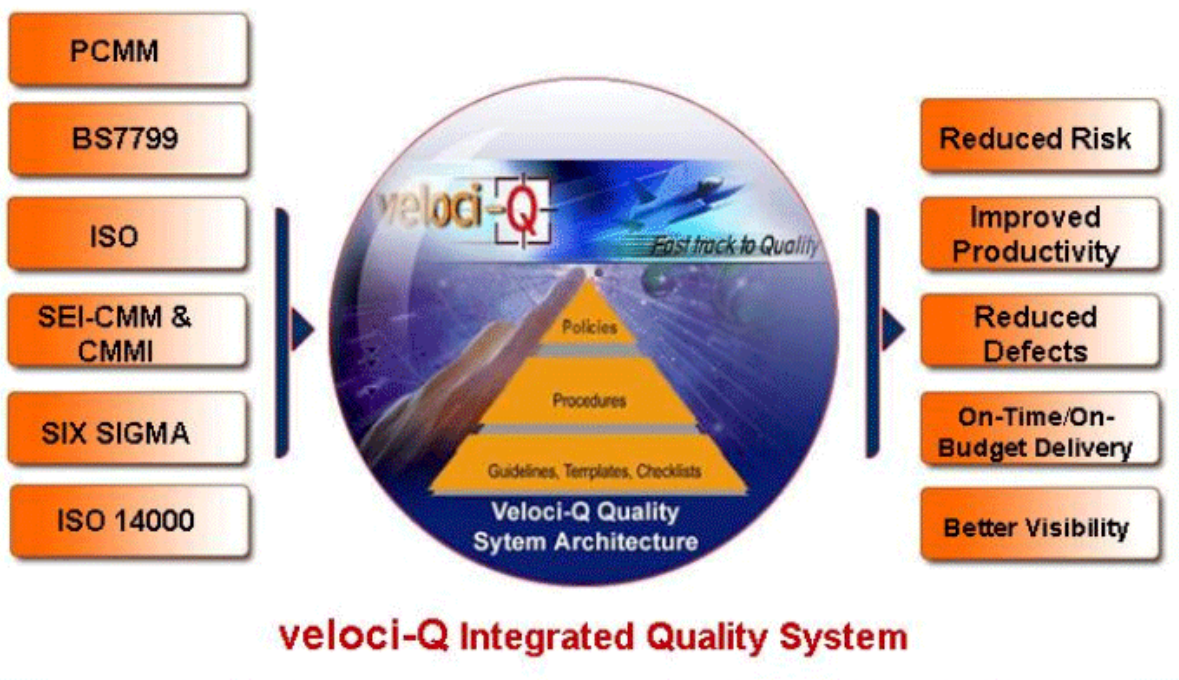

Quality policy:Achieve customer satisfaction by providing defect free products and services on time

Figure 4: Unified Quality System 


\subsection{Improving People Processes}

Although good processes are important, "good" people are required for effective, accurate, and efficient process performance. With the advent of the new century and the growing size of the organization, it became imperative to have processes to help hone organizational capabilities and integrate people with processes and technology. Wipro needed to have a global framework for people processes that would help us enhance competencies within the organization for better business results. Recognizing the fact that people, processes, and technology all contribute to organizational competency, Wipro focused on the improvement of people management. Processes were being taken care of by other quality initiatives, and technology was being developed with investment in research. We realized that people competencies had to be consciously developed for organizational effectiveness, and all human resources (HR) processes (such as recruitment and selection, compensation, progression, development, and succession) had to be integrated towards this end.

While Wipro was practicing processes towards this goal, we decided to align with the PCMM framework [Curtis 01] to ensure that existing gaps were bridged and processes were standardized across the organization.

The P-CMM helped us successfully address critical people-process issues and improve the maturity of workforce practices. It resulted in the establishment of a program for continuous workforce development, integration of workforce development with process improvement, and finally promoting a culture of excellence and innovation. P-CMM Maturity Level 5 certification signifies Wipro's commitment of the highest order towards its people.

Key benefits of P-CMM included the following:

- matching development of employee competencies with changing business needs

- providing employees with a proactive career management tool

- on-time, on-budget project deliveries, regardless of size and complexity, to customers

\subsection{Integrating Software, Systems, and Products}

Prompted by business needs, Wipro soon began undertaking the execution and management of more projects in the areas of systems integration, technology infrastructure, and systems engineering. The process focus for such projects demanded a different perspective. The lifecycle models, templates, and other process assets did not address the needs of such projects adequately. The processes that were being followed by such projects lacked consistency. Wipro needed to increase its focus on these projects and broad-based processes related to systems engineering, software engineering, and integrated product development. To further optimize some of the processes already being practiced, and to ensure standardization across the 
organization, we adopted the CMMI framework developed at the SEI for enhancing software, systems engineering, and integrated process and product development practices [CMMI 02].

CMMI implementation was recognized as an important tool for process improvement and was made a part of the Quality Strategic Plan for the year 2001-2002. The journey commenced with the formation of several process owner teams consisting of both quality group members and practitioners.

The key activities performed were as follows:

- Gap analysis and recommendation phase

In this phase, process action teams, which are composed of members from the quality function and projects, identified the gaps in the quality system with respect to the CMMI framework and proposed solutions to address those gaps. Further, the practitioner teams reviewed the proposed solutions and provided recommendations.

- Implementation and transition phase

Based on the recommendations, the SEPG made required enhancements to the quality system, and detailed release notes were made along with the transition roadmap. The project teams revised the project plans and made necessary process changes. Training programs were conducted across the organization, to highlight new concepts from the CMMI and to facilitate easy transition.

- Training and evaluation phase

An appraisal team consisting of practitioners and members of the quality group was identified and trained in the SEI Standard CMMI Appraisal Method for Process Improvement $\left(\right.$ SCAMPI $\left.^{\mathrm{SM}}\right)$ appraisal method [SCAMPI 01]. This team was lead by an SEI-authorized lead appraiser, and the appraisal was conducted in May 2002 covering all business units under Wipro Technologies. Wipro's process capability was certified to be at CMMI maturity level 5 .

The implementation of CMMI led to the following benefits:

- integrated processes for systems development

- reduced costs resulting from better decision analysis

- innovative process and technology improvements

- fewer defects in project deliveries

- delivery on schedule

- $\quad$ assured product quality due to

- early capture of requirements

- better design through the use of Six Sigma methodologies 
- improved testing as a result of integration planning and enhanced verification and validation processes

- focused and integrated teams delivering value to customers through project-shared vision

- creation of a better organization environment for multi-disciplinary teams to integrate and perform cohesively

\subsection{Information Security}

The importance of information security came to the forefront after the September 11 attack on the World Trade Center in New York. Customers wanted assurance regarding information and physical security. To provide this assurance, we needed to understand and measure the threats and vulnerabilities to information security assets, as well as the implications for these assets. Controls needed to be put in place to manage risks. As shown in Figure 5, Wipro had a dedicated Information Services Management Group responsible for ensuring information and network security, but Wipro wanted to benchmark its processes and align with recognized international standards focusing on information security.

Wipro decided to adopt the British Standard 7799 (BS 7799), primarily for the following reasons:

- Build business confidence with customers and leverage business benefits.

- Develop an easy and flexible architecture.

- Develop and follow best practices in information and physical security.

\section{- Information Security Policy \\ - Security Organization \\ - Security Training \& Awareness \\ - Physical \& Environmental Security \\ - Access Control \\ - Information Classification \\ - Asset Classification \& Control \\ - Personnel Security \\ - Systems Development and Maintenance \\ - Business Continuity Management \\ - Security Incident Management}

Figure 5: Information Security Management System (ISMS) 
The following key drivers were considered as pillars of information security:

- confidentiality — ensuring that information is accessible only to those authorized to have access. Examples include the following:

- ensuring information accessibility to authorized users through proper identification and authentication controls

- safeguarding the privacy of personnel information

- protection of intellectual property rights

- integrity—safeguarding the accuracy and completeness of information and processing methods. Examples include the following:

- ensuring the accuracy and completeness of information through internal processing controls

- ensuring statutory, regulatory, and contractual security requirements

- availability — ensuring that authorized users have access to information when required. Examples include the following:

- providing information access without interruption to authorized users

- protecting information and assets through constant monitoring and reviews

- faster recovery of business-critical resources from major disasters or failure

Wipro received the BS 7799 certification as part of its ongoing quality journey. 


\section{Implementation of the Total Quality Framework}

Wipro's quality framework is optimized simultaneously along five interrelated dimensions, which are shown in Figure 6.

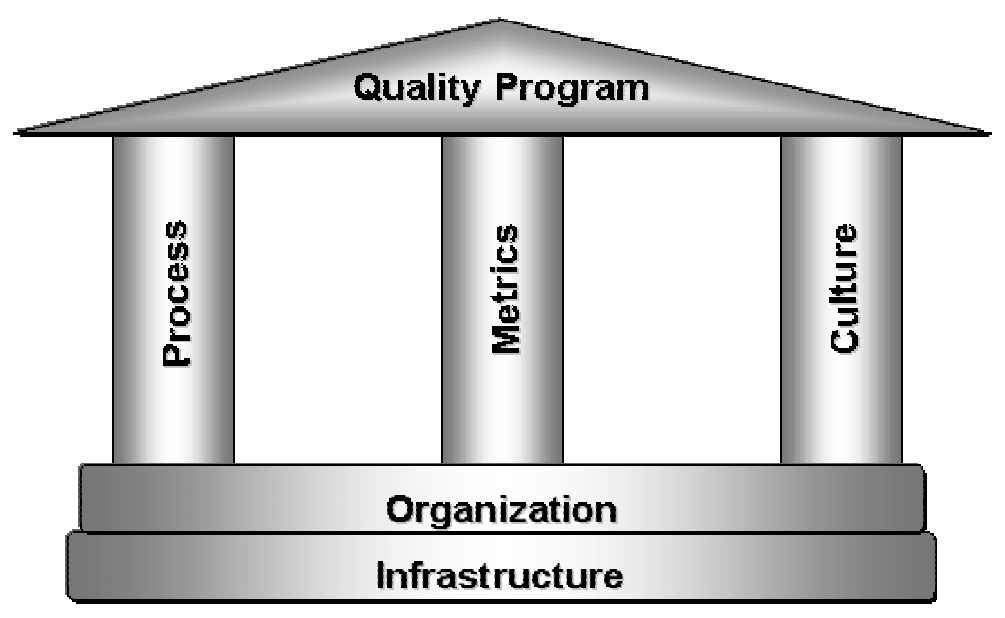

Figure 6: Implementation of Total Quality Framework

During all the process initiatives undertaken by Wipro, all five dimensions have been optimized simultaneously, though incrementally. The facets of the dimensions for continuous quality improvement are as follows:

- Process

- simple, flexible processes that are easy to follow and implement across a wide range of projects

- continuous improvement to processes, driven by practitioners

- Organization

- empowered quality organization with clearly defined roles and accountability

- Culture

- accountability at every level in the organization

- awareness and involvement in quality initiatives by practitioners 
- Infrastructure

- centrally managed, comprehensive process tools

- Metrics

- data-driven approach to quality improvement

- continuous measurement and analysis

These dimensions for continuous quality improvement are elaborated in the following sections.

\subsection{Process}

The process pillar has grown steadily throughout the quality journey. The emphasis has always been on aligning processes to conform to internationally recognized standards, based on the business need and applicability to projects. Process enhancement is triggered not only from within the organization but also by benchmarking in the industry.

Processes have been defined with a clear focus on implementation. Process definition has been characterized by active participation from practitioners in terms of issues, practical applicability to project requirements, and continuous improvement. The key features that ensure effective processes are as follows:

- A simple quality system was developed that is intuitive and easy to understand.

- A vast repository of process assets is maintained that includes the following:

- coding standards

- model documents

- metrics and project data

- Flexibility has been increased.

- Processes focus on "what" is to be done, rather than "how."

- Recommendations are provided to capture the essential "hows."

- Projects have flexibility to define activities with appropriate justification.

- Exhaustive guidelines are provided to address the implementation of processes.

- Over the years, the number of life-cycle models has increased, with a focus on flexibility and tailoring to cater to the variety of projects executed in Wipro. Today, veloci-Q has more than 10 standard life-cycle models, catering to development, maintenance, service, and testing type of projects. Apart from standard life-cycle models, group-specific processes have also evolved, to cater to the unique needs of a group of similar projects to align to specific customer requirements. 
- Project planning and management were optimized as processes became mature. From one project plan template, Wipro now has a variety of templates to cater to differing project scenarios. Project review meetings have also been formalized and regularized. The introduction of project-specific metrics enabled stronger tracking and measurement of individual projects.

- Defect prevention activities gained focus by the introduction of look-ahead meetings to identify issues proactively. Defect prevention activities are conducted at the organization and project level on a regular basis. Risk management processes grew more robust over the years.

- Review and testing processes were strengthened to include the entire range of activities, by the introduction of relevant templates and models.

- Six Sigma projects were executed to address problems faced in critical business areas (e.g., requirements development, server optimization, tools monitoring, service improvement, and product performance).

- As shown in Figure 7, engineering processes were enhanced by the use of Six Sigma tools like Voice of Customer (VOC), Kano Model, Quality Function Deployment (QFD), Pugh Matrix, and Failure Mode Effect Analysis (FMEA).

- Regular audits and assessments are conducted to ensure compliance. Project-level assessments are also enabled for regular heath-checks.

- Importance has been given to industry-recognized certifications. Wipro has undertaken an initiative to get all its project managers certified by the Project Management Institute (PMI).

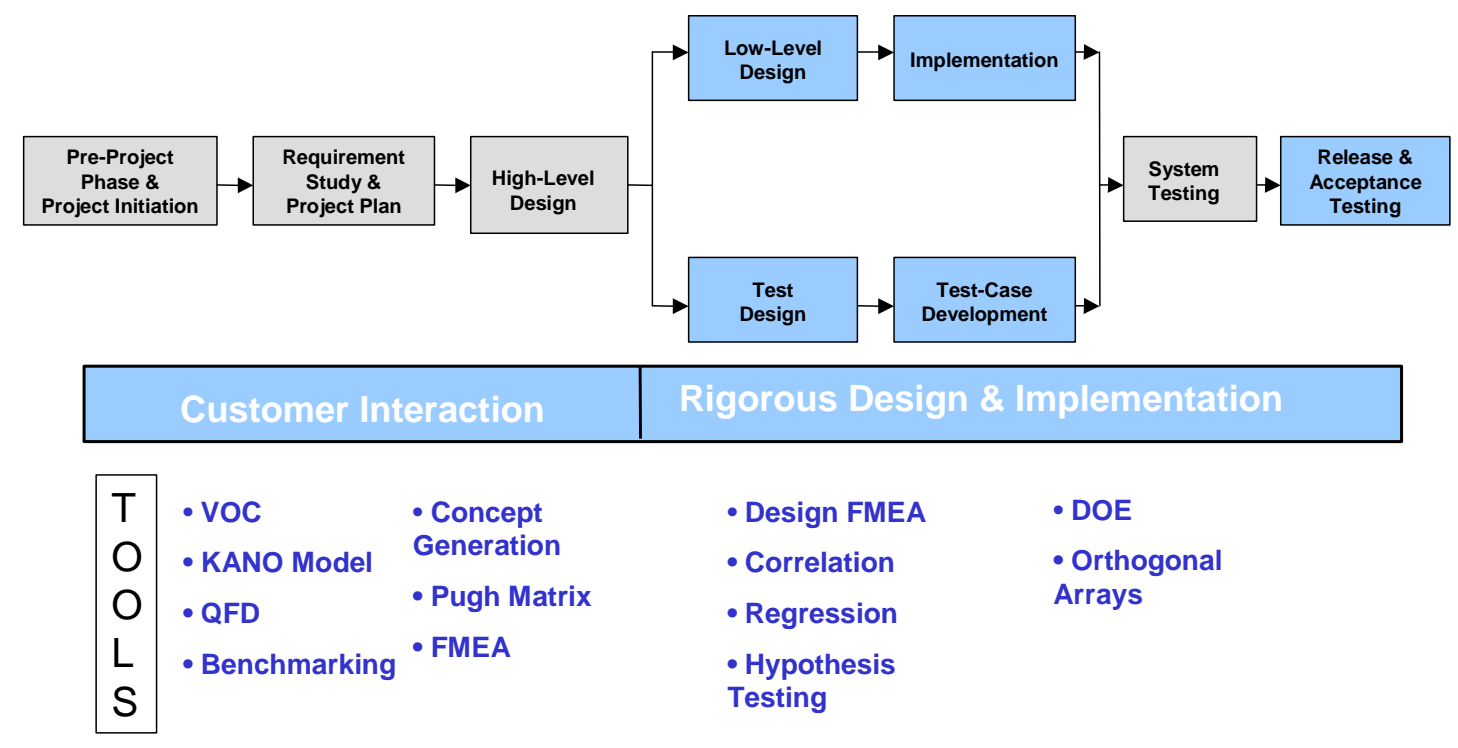

Figure 7: Six Sigma in Project Execution 
As shown in Figure 8, the following process steps are typically performed during project execution:

- When a project is initiated, the project manager identifies the life-cycle model that will be followed for executing the project. The project manager selects the life cycle for the project from one of the over 10 Quality Assurance (QA)-approved application development life cycles. This is the first level of tailoring enabled by the quality system, to cater to specific project requirements.

- A custom project plan is assembled for the selected life cycle, incorporating key elements of the CMM/CMMI Maturity Level 5 process. The phases of the project and activities are tailored, and the project's defined process is documented in the project plan. Appropriate entry and exit points are defined for each phase, with the identification of key metrics to monitor and manage the project.

- A formal project plan review is conducted, with the quality representative serving as a mandatory member of the review team. The project manager is given a docket of the possible tools that can be used across the project's life cycle.

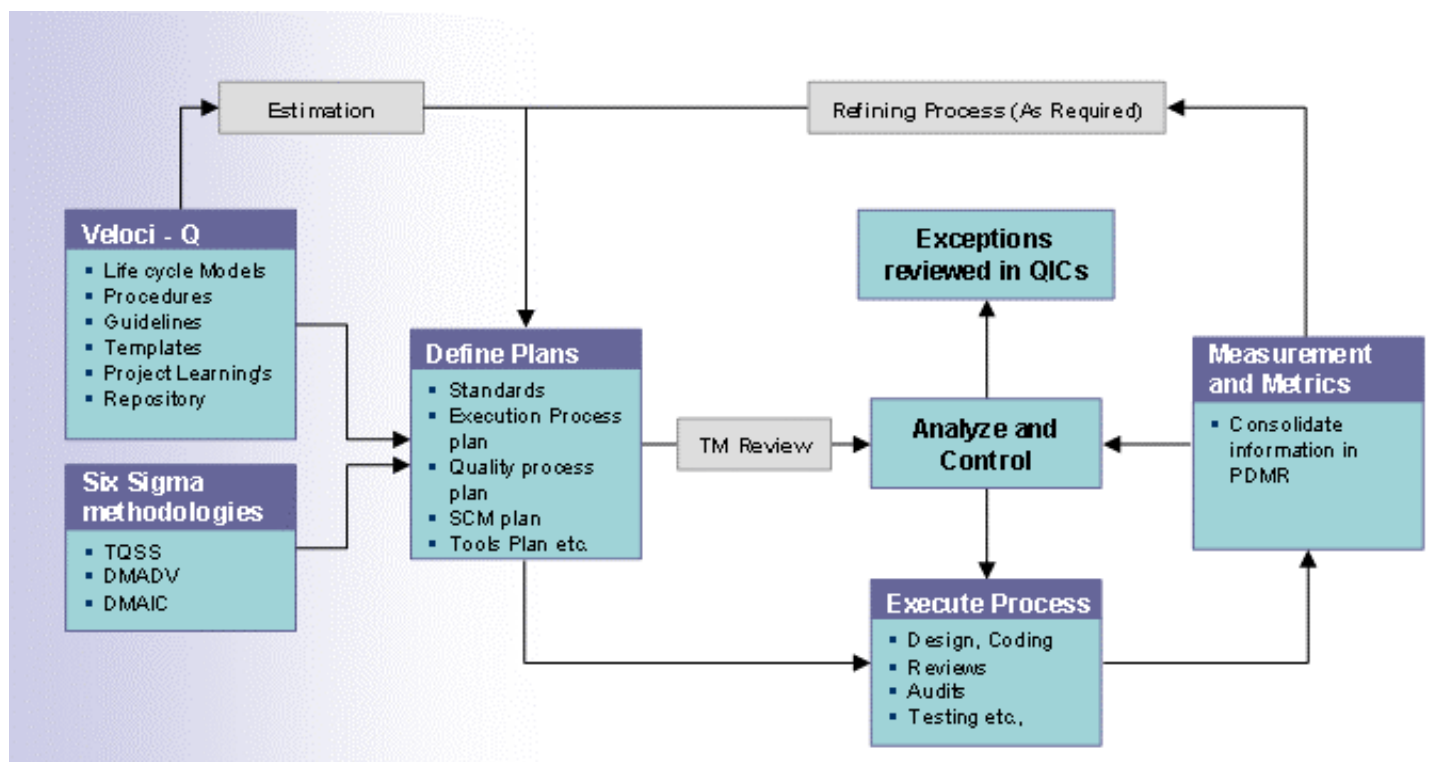

Robust processes and project management to ensure timely delivery and quality

\section{Figure 8: The Project Execution Perspective}

- The project plan identifies critical project metrics and forms the base for monitoring project progress. The metrics of the projects are captured monthly in the Project Data and Metrics Report (PDMR), and project progress is monitored against the plan on a monthly basis by using the Project Monitoring Report. 
- The project's compliance towards the project's defined process is checked periodically by using the CMMI-Process Area (PA) Rating Checklist. The CMMI-PA Rating Checklist has questions pertaining to each PA. After completion of each phase/milestone, the project is checked against the relevant PA.

- Additionally, internal and external audits are conducted once every quarter. Internal audits are conducted by Wipro Technologies-trained internal auditors. External audits are conducted by Det Norske Veritas (DNV), an independent evaluation service. Every project is audited at least once during the project life cycle.

- A mandatory configuration audit is performed before the release of each deliverable. The findings are recorded and tracked to closure in the Software Configuration Audit Report.

- A test audit is conducted to verify completeness of testing prior to the release of the software.

- At the close of the project, its performance is captured during the Project Performance Analysis (PPA), in the Project Performance Report (PPR), which includes a comprehensive postmortem of the project by all team members, including the quality representative. Customer feedback is also reviewed. The project team meets as a group to share their views and experiences from the project, which typically includes

- analyzing the performance of the project

- capturing the best practices and lessons learned from the project

- what went right, what went wrong, what could have been improved, and what could have been avoided

- ensuring all data reported are correct and up to date

- The following records generated during the project execution are used during PPA meetings:

- Project Metrics and Data Report

- Project Monitoring Report

- CMMI Process Area Checklist and Audit Reports

- customer feedback on the project

- On completion of the PPA and sign-off by the project manager and the QA manager, the Project Performance Report is generated. The information captured in the PPR is updated on the Web site for future reference.

\subsection{Organization}

The quality function at Wipro is carried out by an independent group with the objective of defining, maintaining, improving, and ensuring adherence to the processes and procedures 
defined in the quality system. To this effect, the quality function is organized as shown in Figure 9.

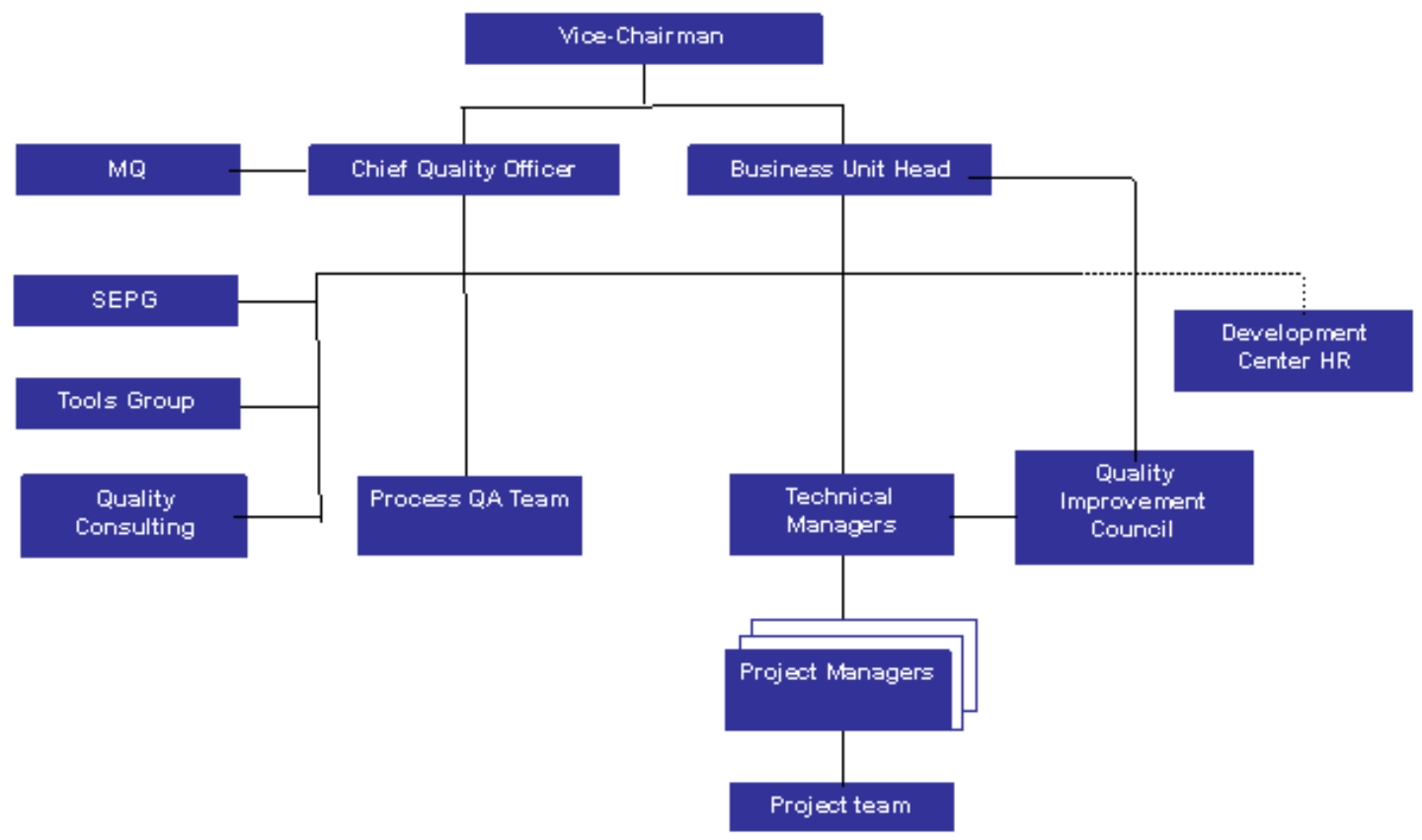

Figure 9: The Quality Organization

- Mission Quality (MQ)

This group was constituted in 1997, to facilitate Six Sigma initiatives within the organization. This group is responsible for training and enhancements to Six Sigma methodologies and concepts.

\section{- Software Engineering Process Group (SEPG)}

A centralized group in Wipro, this group is responsible for defining process assets, maintaining the quality system, and coordinating process improvement activities. The SEPG facilitates and provides support to projects for consistently using the quality system and process assets. The SEPG collects and analyzes metrics for all projects being executed in the organization and also arrives at metrics norms. The SEPG was constituted during the CMM-focused part of Wipro's quality journey and, since then, has grown considerably in terms of the range and scale of activities managed.

The SEPG has three focused groups-Process Performance Evaluation Group, Process Verification and Development Group, and Engineering Methods Group. The SEPG has dedicated, full-time resources with a range of skills, including statistical analysis for metrics analysis and benchmarking and Web designing for maintaining the Web-based quality system and related process assets and tools. 
Apart from full-time SEPG resources, practitioners also spend considerable time and effort in organization-wide process-related activities. Task teams, which are composed of practitioners for new quality initiatives (such as enhancing coding standards, ensuring CMMI compliance with respect to projects, etc.), have ensured adequate support and effort towards quality initiatives.

\section{- Tools Group}

A centralized group in Wipro, this group is responsible for driving tools usage across the organization. This group continuously helps in automating the quality system processes. Another charter of the tools group is to assist project teams in the deployment and the effective use of tools in addition to solving technical problems for identified tools.

\section{- Process Quality Assurance Team}

The process quality assurance team ensures that all projects being executed comply with the processes defined in the quality system. They ensure implementation of the quality system, which is defined by the SEPG.

\section{- Quality Consulting Group}

This group transfers the immense knowledge acquired over the years in our quality journey to help organizations reap the benefits of employing quality-oriented processes. This group offers the complete spectrum of quality consulting services to customers-from recommending the right quality framework for a client's business, to guiding and implementing systems and processes that are vital to reaching their desired quality destination.

Each project has a project manager and a quality representative assigned to it.

The project manager has the responsibility of overall project execution, while the quality representative has the overall responsibility of ensuring defect-free deliverables by defining and implementing quality assurance processes and procedures for the project.

As processes matured, the introduction of a quality representative for a project emphasized the focus on the quality function at the project level. The definition of roles and responsibilities for a separate test team within a project emphasized the importance of differentiating between testing and development.

The quality group also conducts training on the quality system and facilitates sharing of knowledge and best practices among all projects in the organization.

Quality as a culture has been promoted at all levels in the organization. The goals and objectives of each employee are aligned with the business. Quality goals and objectives are translated from Vice Chairman to Chief Quality Officer (CQO) and from the CQO to the quality groups (SEPG, Process QA). The CQO's quality goals and objectives are also aligned with those of individual business unit heads, which are propagated down to the individual project level. 
Senior managers (business unit heads and technical managers) form the vital link between the customers and the employees. They are the role models for their group members, in terms of interaction with customers, achieving and maintaining quality norms, and inculcating a quality culture in the group. Technical and project managers drive the collection of data on customer satisfaction, schedule, and defect metrics for projects.

Senior managers periodically review projects. Every month, the business unit head participates in Quality Improvement Council meetings, in which all technical and project managers take part. In this meeting, issues like defect control, customer complaints, and root cause analysis are discussed, and action items are tracked to completion.

Senior managers are directly involved in driving major quality initiatives within the organizations. The most recent of these initiatives are CMMI certification and implementation of Six Sigma methodologies in projects. They also ensure that objectives are set for each team member and that appraisals are performed and discussed with each team member during the end of the appraisal period.

\subsection{Culture}

Appreciation for quality is widespread in the organization, permeating to every practitioner. Ownership and accountability are prevalent at every level in the organization. Every individual has quality-related goals and objectives and is encouraged to contribute actively towards quality initiatives. This involvement is supported by the intranet and Internet availability of the quality system, process tools, and knowledge repositories.

The extent to which an organization derives benefit from the process improvement initiative depends on the degree to which the organization complies with the quality system. As the extent of institutionalization increases, the payoff also increases. There is no unique, direct, or easy method to ensure smooth implementation of processes in any organization. The approach to be taken depends on the culture prevalent in the organization.

Wipro's process improvement model has ensured a highly motivated workforce with an attitude of openness to change and passion for process. In all process initiatives, there has been a conscious involvement of practitioners, by means of participating in task forces and core teams for process definition and reviews. Bottom-up process definition has helped in getting better buy-in. Before new processes are introduced into the quality system, they are thoroughly reviewed; review members play the role of "devil's advocate" during these reviews and try to seek justification for the changes introduced. This helps to anticipate the questions that are likely to be raised during implementation.

Organization-wide involvement has grown over the years, with participation from all levels-from project team members to senior managers, and to business unit heads. The composition has been in line with process goals, with a judicious mix of quality group members to 
facilitate the team. Internal audits and assessments are also conducted by practitioners trained in audit and assessment methodologies.

Organization-wide quality awareness has been achieved by regular updates on intranet sites and broadcast mails on the status and key features of process improvement initiatives. Quizzes, contests, and FAQs further bridge the gap between practitioners and quality, particularly during the evolution of veloci-Q and CMMI implementation.

The quality culture is also strengthened by a focus on process-related training imparted across the organization. Role-based training, software engineering programs, and quality system overviews are an integral part of every practitioner's charter. Updates to process tools and the quality system are also communicated by means of Quality Improvement Councils (QICs) and broadcast mailers. QICs are structured forums, focusing on the quality and process issues in every business unit. Metrics, best practices, and project performance are discussed. New initiatives are also highlighted.

A large number of Black Belts for Six Sigma methodologies are practitioners, who facilitate Six Sigma projects. Six Sigma methodologies are also propagated to the project level, with project managers and senior practitioners leading Six Sigma projects.

People involvement is particularly significant in the continuous improvement of processes. Process improvement proposals (PIPs) are used as drivers for process improvement at Wipro. Software processes are improved continuously based on project practices. All practitioners have access to the Web-based PIP tool (shown in Figure 10) from their desktops and are free to propose suggestions for new processes or changes in existing processes. The categories vary from bug fixes/enhancements to new process introduction (quality system, project data bank, etc.). Suggestions for continuous improvement can emerge from any of the following channels:

- $\quad$ rocess improvement proposal from practitioners

- Management Review Meetings

- SEPG

- business requirements

- audits and assessments

- Quality Improvement Councils 


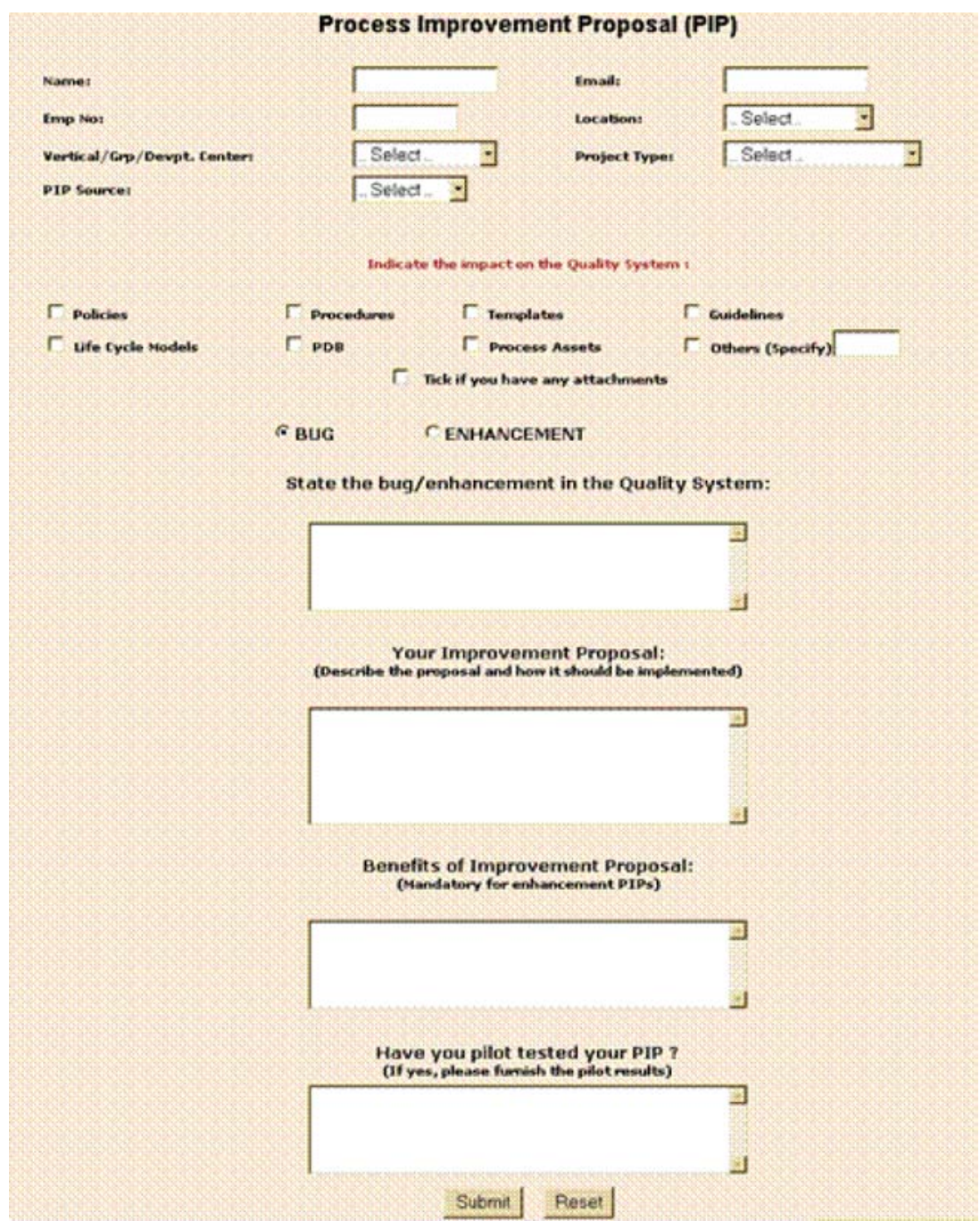

Figure 10: PIP Screen

The SEPG manages all PIPs and constitutes a PIP board to decide on implementation of PIPs. The PIP board consists of practitioners and quality group members. On closure of a PIP, mail is sent to the practitioner on the actions taken on the PIP. Alternatively, practitioners can view the PIP repository to see the status of process improvement suggestions.

Typically, PIP board meetings are conducted on a quarterly basis and a consolidated veloci-Q release is made. Communications of new releases and PIPs considered are sent by means of an organization-wide broadcast mail. The "What's New" section within veloci-Q also contains information on regular releases of the quality system, thereby ensuring that all practitioners are kept updated on continuous improvement activities. 


\subsection{Infrastructure}

Wipro's quality approach ensures that systems are in place to ensure the capture and dissemination of invaluable knowledge. The opportunities for improvement, which are primarily derived from project experiences and industry-wide best practices, give an effective platform for increased process optimization and enhanced satisfaction for customers and project teams. The other dimension is the process automation component (i.e., the extent to which various process elements defined in the quality system are automated). This infrastructure is an important factor for increasing compliance levels and the benefits associated with doing so. To achieve these benefits, Wipro has steadily enhanced its infrastructure to support process improvement initiatives.

\subsubsection{Integrated Process Automation}

Integrated Process Automation Tool (iPaT) is a Web-based project management tracking tool, developed and maintained in-house. With more than 10,000 employees, 14 development centers, over 1,000 projects, and a holistic quality system catering to a diverse variety of projects, it became imperative to manage metrics and project development in a streamlined manner.

Wipro decided to improve the following factors:

- senior management visibility of project status

- effort in documentation and collection of data

- effort spent in consolidating metrics data

- resource utilization

- consistency and accuracy of data

- coordination effort by the SEPG, the Process QA, and managers in obtaining relevant data for decision making

iPAT is a single window for the entire project life cycle from initiation to closure. The tool is a storehouse of process assets such as templates, checklists, and process models, as per veloci-Q. iPAT is integrated with the organization's Human Resources database for team details, audit tool for non-compliance closure details, and Wipro's knowledge management system for Project Data Bank (PDB) data. iPAT is used by every practitioner, from project team members to the quality group, including senior management. Team members use iPAT to update work plans; testing teams use iPAT for managing testing activities; and project managers use it for monitoring project status and activity management. iPAT provides an automatically generated metrics scorecard at the end of the project and provides for an online approval mechanism. The integrated metrics scorecard generated by iPAT ensures better alignment with business objectives by generating statistical graphs for objective decision making. Apart 
from the generation of project-tracking reports like PDMR and PPR, it also generates comparisons between process and product metrics. The quality group and senior management use iPAT for metrics consolidation to enable effective decision making.

The features and benefits of this process automation tool are depicted in Figure 11.

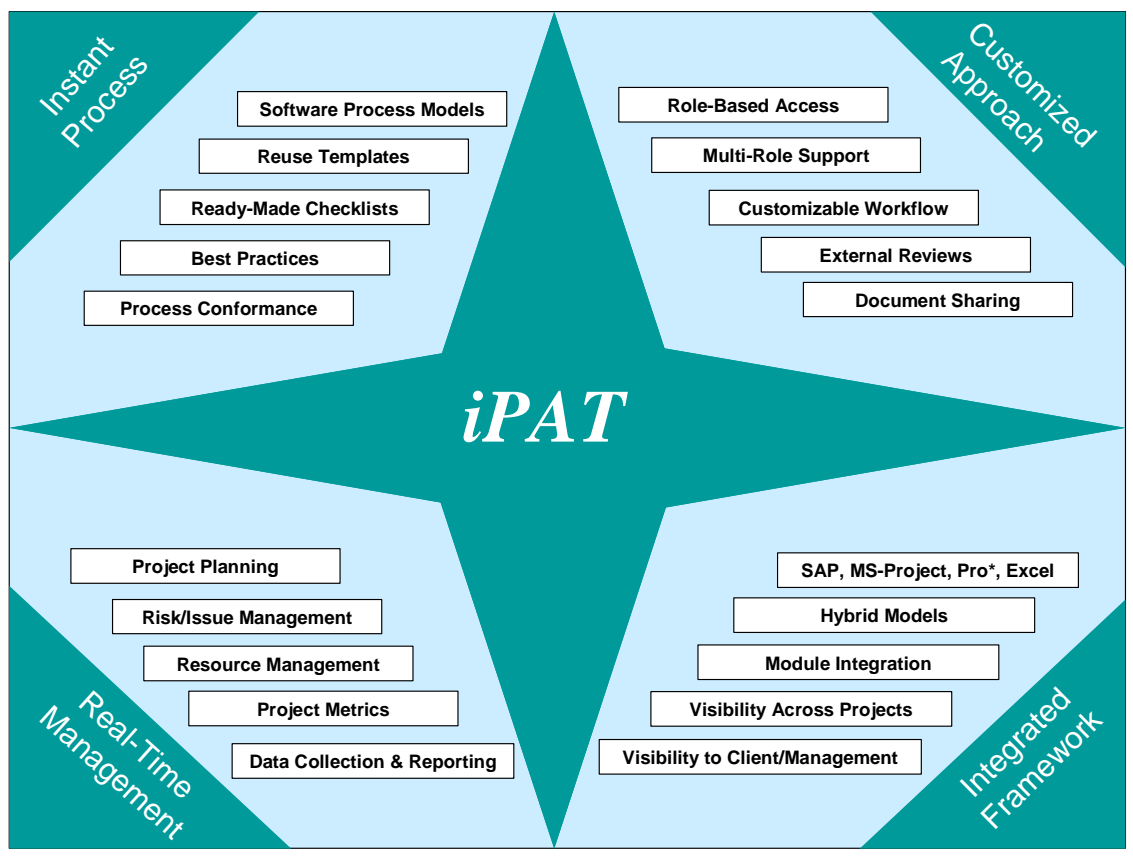

Figure 11: iPAT Features

\subsubsection{Project Data Bank}

The Project Data Bank is the central repository of information from projects collected across the organization. PDB provides historic project data and enables organization-wide knowledge sharing at the click of a button. Data from all closed projects have an entry in the PDB, making it an extensive storehouse of around 1,000 projects, with more being added at regular intervals. Data extracted from Project Performance Reports, Project Data and Metrics Reports, and Project Plans are made available in the PDB. The PDB is available through Wipro's enterprise-wide knowledge management system, KNet.

Equipped with a query-based interface, PDB can be used to retrieve data based on several parameters (e.g., project code, project type, account, application area, development operating system [OS], database, language, and business unit). Data from PDB can be retrieved through an Excel download interface to perform a metrics analysis at regular intervals. Typical results from a PDB query are shown in Figure 12. 
PDB facilitates not only accurate estimation and planning, but also better awareness of the possible risks and challenges likely to be faced during project execution. This information enables project teams to be better prepared with proactive solutions for the risks. Reference to $\mathrm{PDB} / \mathrm{KNet}$ has become such an integral part of the system that it forms part of the activity checklists during planning and estimation processes.

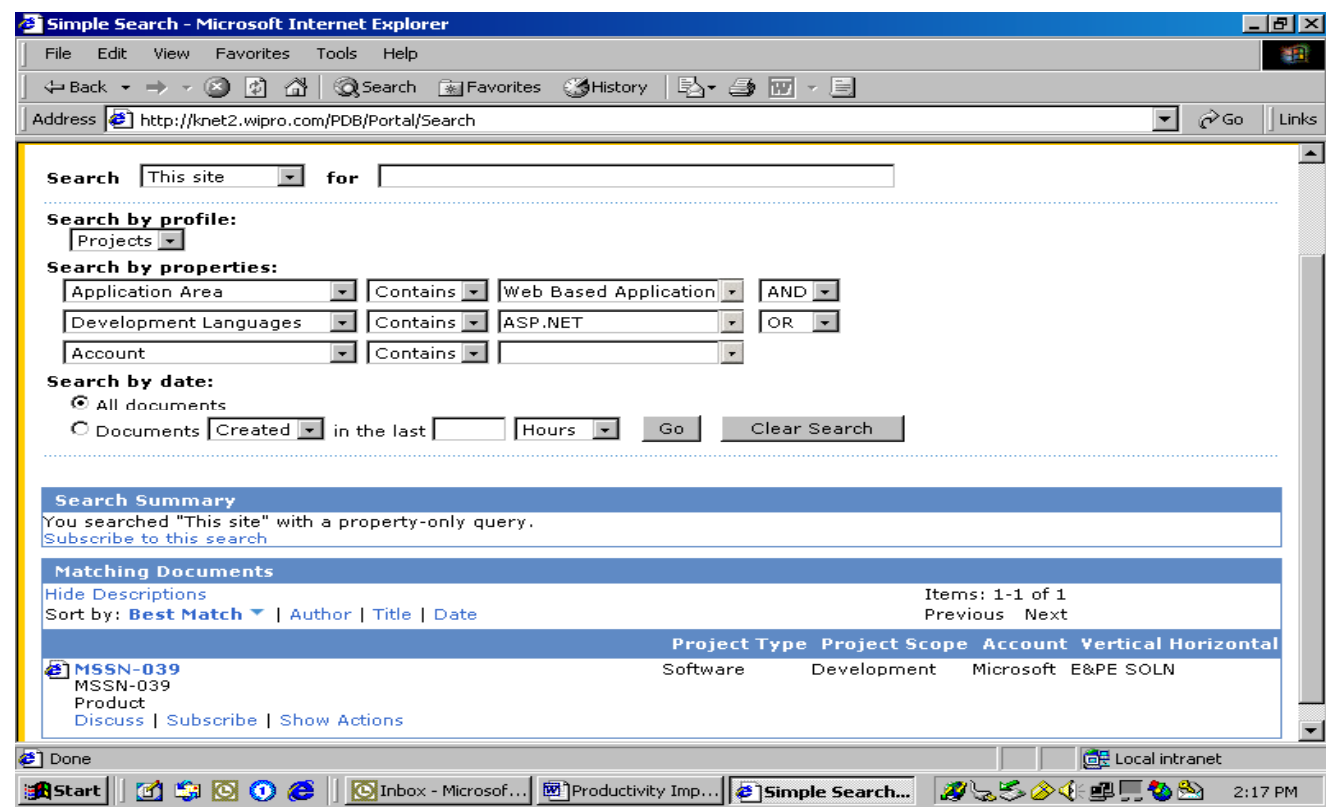

Figure 12: Query Results in PDB

\subsubsection{Audit Management}

Audits in Wipro are planned and executed using a Web-based tool, which allows centralized planning and management of all audit-related activities. The audit tool has facilities to upload lists of projects for audit, manage auditors, and modify audit details. The tool supports the full non-compliance report closure life cycle-from auditee to supervisor, to quality group, to management representative (MR).

The tool facilitates many reports that are used by the SEPG. Some examples are listed below:

- query-based reports

- non-conformance reports

- auditor reports

- observations

- $\quad$ average rating reports

- auditor's feedback

- auditee's feedback 
- $\quad \mathrm{NC}$ (non-conformance)/project reports

- business units

- ISO clauses

- functions

The holistic view provided by this tool facilitates better planning and management of Wipro's audit process.

\subsection{Metrics}

Wipro's focus on a data-driven approach to quality improvement has led to the institutionalization of a broad, robust metrics program. From the project level to the organizational level, metrics are captured and analyzed, and improvements are made based on these metrics.

PDMRs from individual projects provide inputs for metrics analysis at the project, business unit, and organizational level. Quality Improvement Councils are conducted periodically at the business-unit level. Business-unit inputs are analyzed at the organizational level, and the Management Review Meeting forms the basis for data-driven decision making and process improvements.

Wipro's objective of continuously improving productivity with optimum product/service quality directly led to the establishment of processes to achieve productivity improvement. The process steps involved in planning and achieving productivity improvement included identifying and implementing process enhancements based on research and both internal and external benchmarking.

Project data from PDB have been analyzed to arrive at key factors that affect productivity. These factors, built into a mathematical equation with actual past project data, led to the evolution of the Productivity Performance Model. The intent of this model is to provide additional information that can be used by project teams for better decision making. These data can be used to foresee the effect of various parameters on productivity, both at the start of the project and during the project's progress. This model complements the existing estimation and project management methods.

As shown in Figure 13, this model is available as a tool with input parameters like estimated size with unit of measure, technology area, requirements volatility (changes to the baselined requirements), scope for reuse, tools usage, experience of the team, and estimated rework based on the errors estimated to be captured. The tool analyzes the closest match with data from past projects, based on a linear regression equation built into the tool, and provides the productivity that could be expected. 


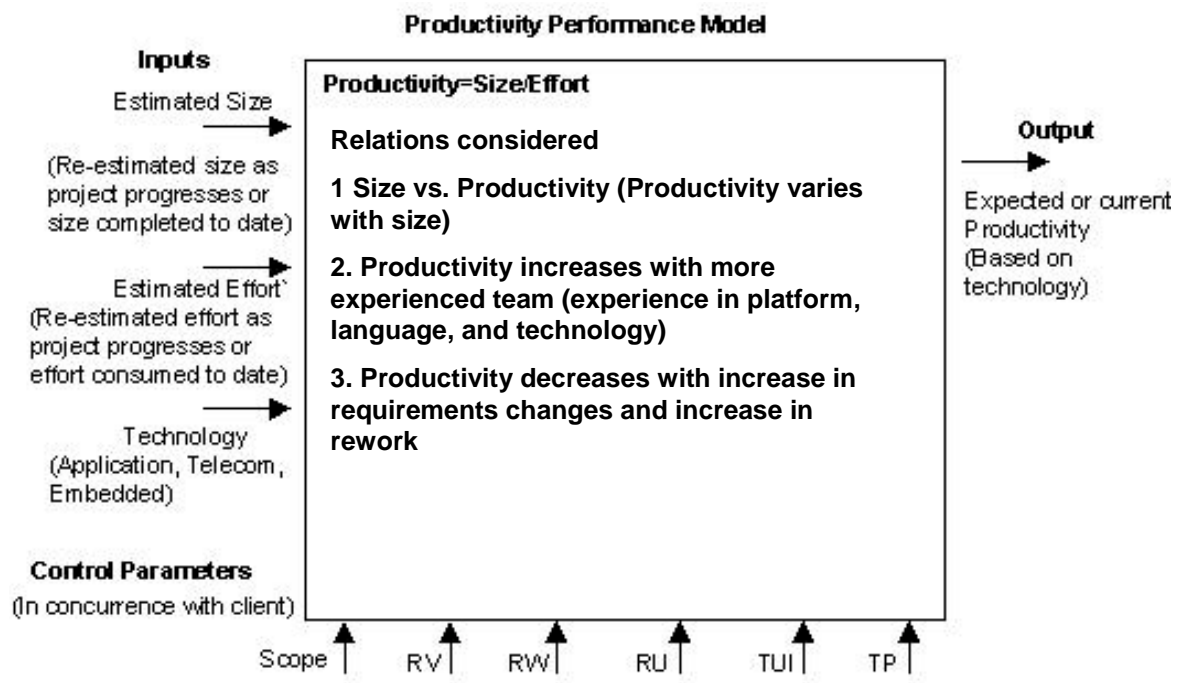

RV: Requirements Volatility, RW: Rework, RU: Reuse, TUI: Tools Usage Index, TP: Team Profile

Figure 13: Parameters in Productivity Performance Models

In addition to the above model, projects also refer to historical project data of similar technology or domain from the PDB in KNet.

Based on the estimated productivity value and use of performance models, projects now have a range available to set targets. To define the project-specific goals from this range, Wipro's goals and the customer's vision are considered, quantified, and aligned.

As shown in Figure 14, projects share the vision of Wipro and the customer in the project plan. The metrics section in the project plan contains the organization norm, the business unit norm, and the project norm. Further, norms are also defined based on the sub-processes that have an effect on the main metric goal/objective. Sub-process goals provide inputs to project teams for effective planning and continuous improvement of productivity. The plan also contains information on tools and methods used that focus on productivity improvements. 


\section{Project Shared Vision}

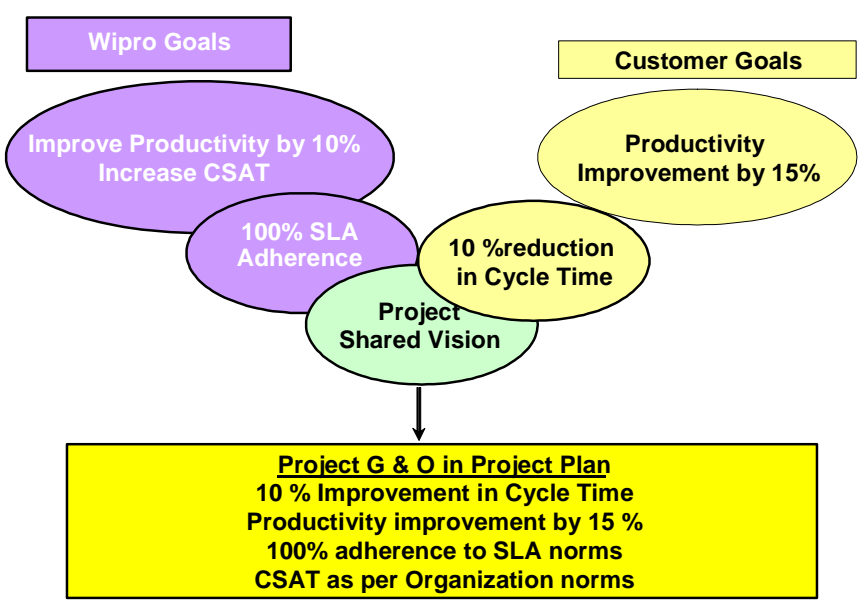

Figure 14: Project Shared Vision-A Sample

The baseline for a project's metrics is revised based on past performance, at least once a year. This baselining takes into account the past performance of the project, benchmarking with similar projects inside Wipro and across the industry.

Wipro-specific data are collected and analyzed on different application areas and technology areas. These data are validated through rigorous statistical analysis. The analyzed data are benchmarked with international publications and with national-level bodies, including the following:

- International Software Benchmarking Standards Group

- Meta Group

- Software Process Improvement Network (SPIN) Bangalore and Hyderabad

Based on the benchmarking exercise, Wipro identified the following areas on which to focus:

- determining ideal effort distribution across SDLC for different types of application areas

- increasing tools usage for code generation

- using tools/methods for requirements capturing and testing

- introducing the concept of design methodologies

- improving the reuse percentage

- reducing the percentage of total effort in testing and increasing the effort for project management 
- reducing the percentage of rework effort

The benchmarking exercise indicated that Wipro benefited in the areas of defect detection at source and optimization of testing time. The execution of test cases and code coverage in testing was optimized using orthogonal arrays and design of experiments (DoE) to reduce the effort spent in testing, while finding more defects. Benefits included the following:

- Phase containment or defect removal efficiency deals with the source at which errors are injected and detected in the project life cycle. If detection happens at the same phase in which the error is injected, then the phase is said to be contained. Phase containment leads to less rework effort, thus contributing to optimum productivity. The current project performance on phase containment is much higher than the industry average.

- Significant reduction in rework effort was realized as a result of enhancements to the review process and procedures, additional checklists, and involvement of domain experts in critical reviews.

- Reuse improvement was realized in specific business units. This improvement was attributed to planning and use of appropriate design methodologies and KNet infrastructure.

- The Tools Usage Index (TUI) has also increased considerably. TUI is a quantified measure of tools planned to tools used in a project.

\subsection{Customer Visibility}

The performance and status of individual projects can be reviewed with customers and key users through Cocoon, Wipro's service management intranet. Cocoon ensures effective communication and regular information exchange.

The extranet site (shown in Figure 15) is a single window for senior management, project managers, and key stakeholders to view the status of the projects and estimate the health of projects. Project management is an important feature provided through the extranet site for easy, online tracking and maintenance of project details. Cocoon provides scalable score cards and dashboards to reflect global operation performance and ensures quick reporting and analysis. Cocoon can also be customized depending on customer needs. Security for the entire system is achieved through role-based access to users. 


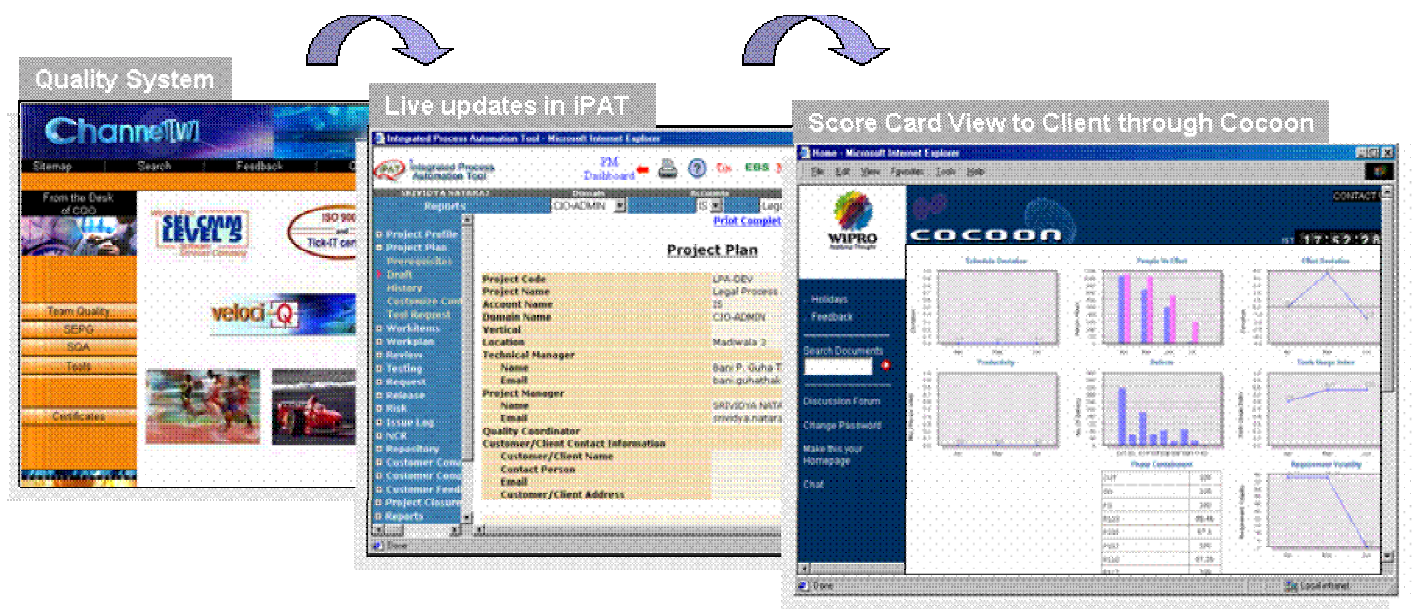

Figure 15: Customer Visibility Through Cocoon 


\section{The Supporting Systems}

The quality approach, veloci-Q, is the core of all the processes. The presence of other systems around this has supplemented the overall process in the organization. These supporting systems have created an organizational environment for integration.

\subsection{Software Engineering Tools}

A dedicated team of tool consultants helps project teams in identifying the tools that can be used in the project. All the tools that are used are made available on a central server, thereby taking care of the licensing aspects. (Examples of the available tools are shown in Figure 16.) A tools lab provides an opportunity for evaluation and demonstration of various tools. Every business unit has a tools representative, who is part of the central tools group, to cater to specific needs of the particular business unit. For each project, the Tools Usage Index is measured to drive tools usage in projects.

\section{Examples of Tools Usage}

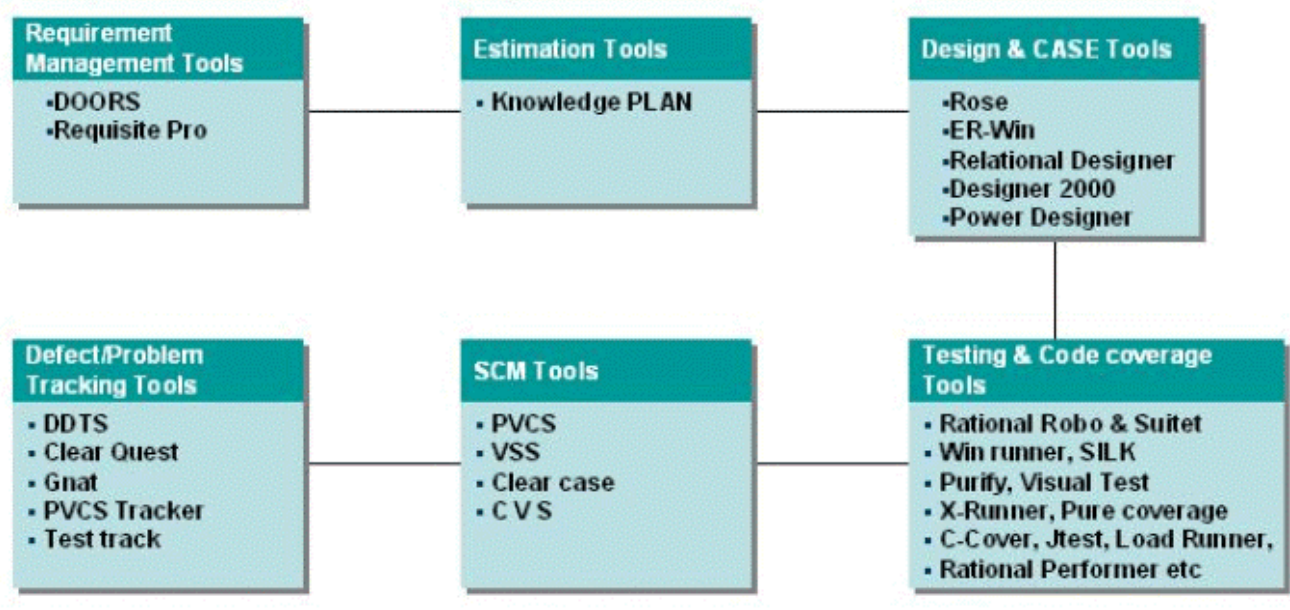

Figure 16: Tools Used During a Typical SDLC 


\subsection{IT Management}

The IT management team is the custodian of the Information Security Management System (ISMS), responsible for data, information, and physical security, as shown in Figure 17. The team manages the hardware and software infrastructure. It also provides services to project teams for smooth execution.

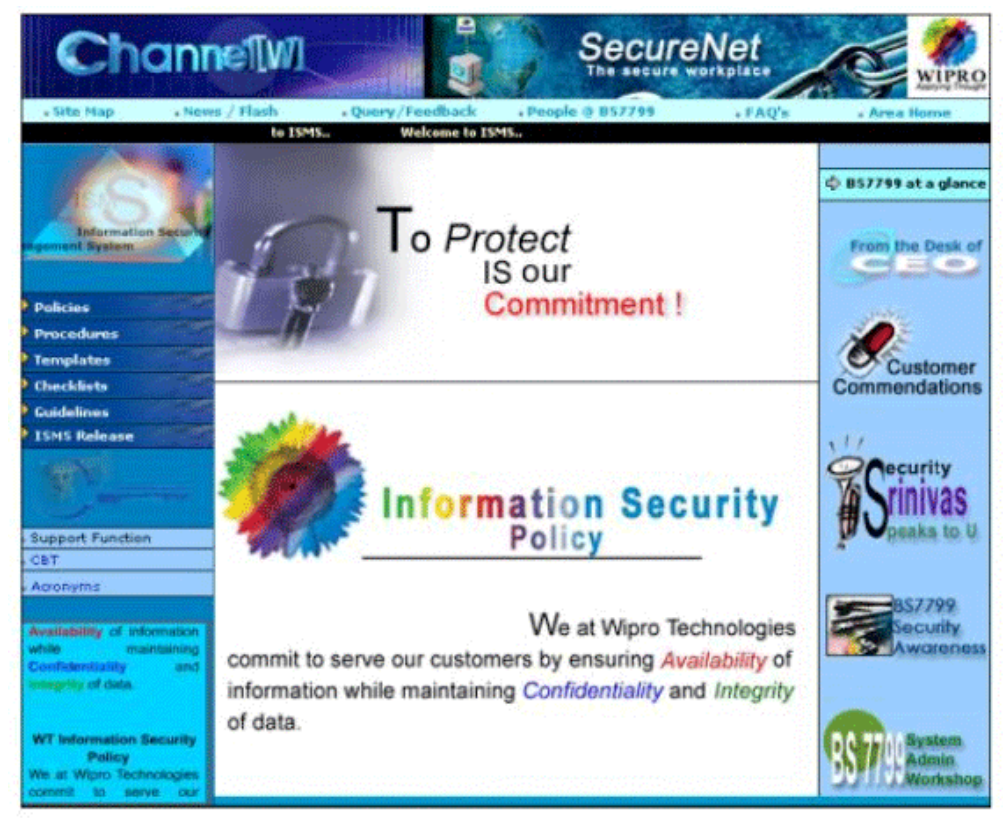

Figure 17: ISMS Portal

\subsection{Human Resources and Competency Framework}

The responsibility and authority of each role in the organization is defined in the quality system. In addition, the competencies required to handle these roles are described in the Competency Framework. These competencies are in line with the People Capability Maturity Model [Curtis 01], as shown in Figure 18. 


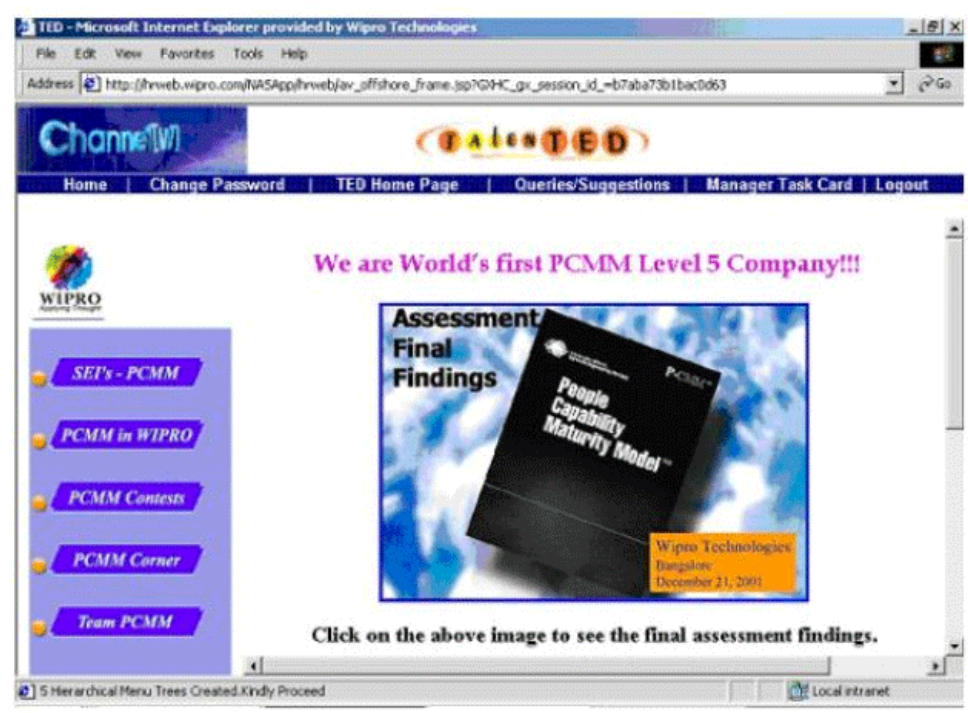

Figure 18: People Capability Maturity Model

\subsection{Knowledge Management Systems}

Knowledge management $(\mathrm{KM})$ is the management of explicit and tacit knowledge with data and information of the object domain to create value. Being in a knowledge-intense industry, good KM systems are important for the management of processes.

As shown in Figure 19, the key aspects of Wipro's KM system are

- connecting people to content

This part of the KM consists of knowledge repositories that include processes for creation, distribution, and use of explicit knowledge. The Reusable Components Repository facilitates the use of previously developed components to reduce redundancy.

- connecting people to people

This part helps in connecting people in need of knowledge to people with knowledge. Lists of experts in particular areas are maintained, and people seek information from these experts.

- $\quad$ best practices for projects

This section contains the quantitative (metrics) and qualitative data for all the projects. 


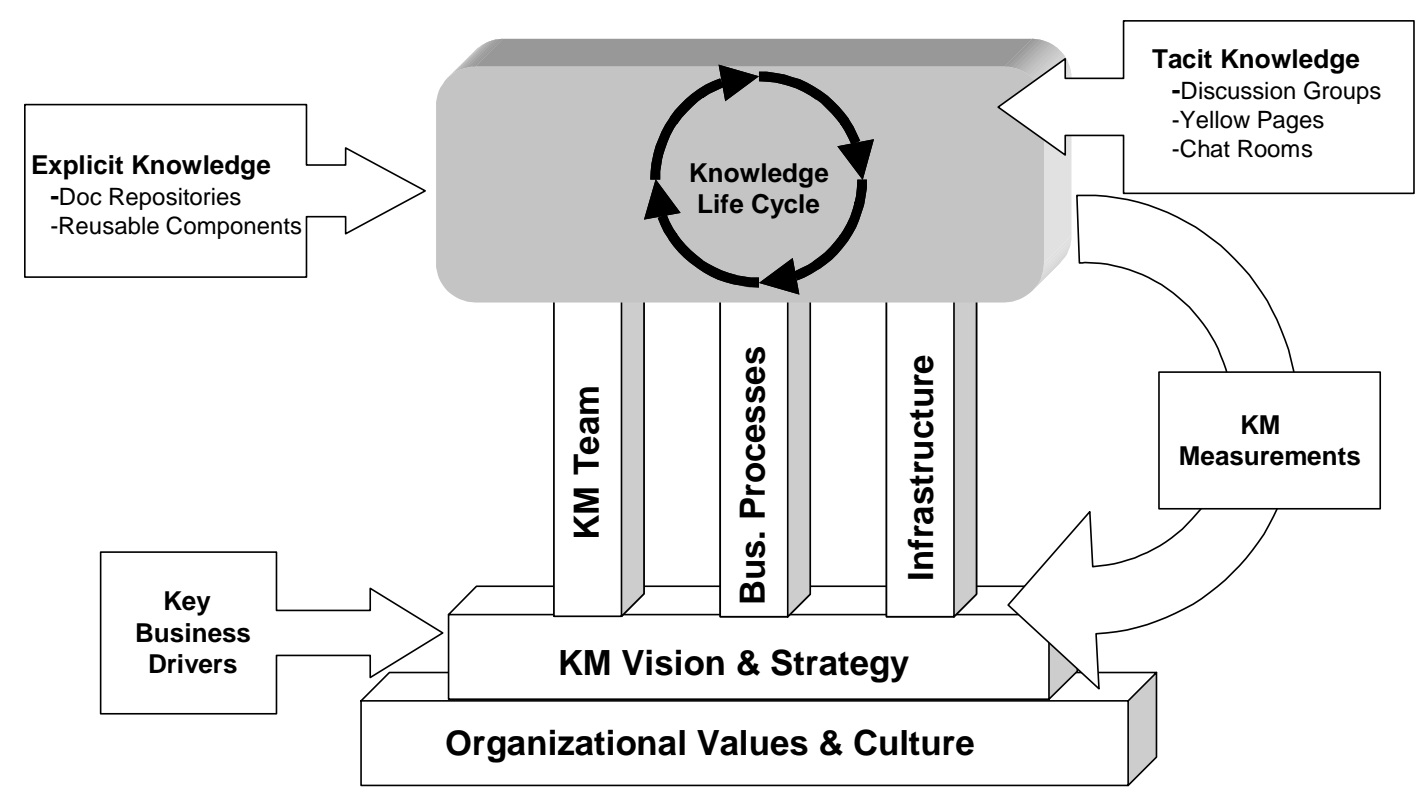

Figure 19: Knowledge Management System

\subsection{Talent Transformation}

The talent transformation team helps in creating a competent workforce that is ready to handle technical and management challenges that are required to execute complex project scenarios. Equal emphasis is given to technical training as well as behavioral training. Language training and cross-cultural skills also form a part of this framework. A dedicated learning center with state-of-the-art classrooms and facilities enables over 1,500 employees to be trained simultaneously. Some other key features are as follows:

- The number of trainers has doubled over the last three years.

- Classrooms have increased three times in the same period.

- A virtual classroom is being deployed for global delivery.

- On average, 75,000 person-days of training are provided every year.

The key aspects of talent transformation are shown in Figure 20. 


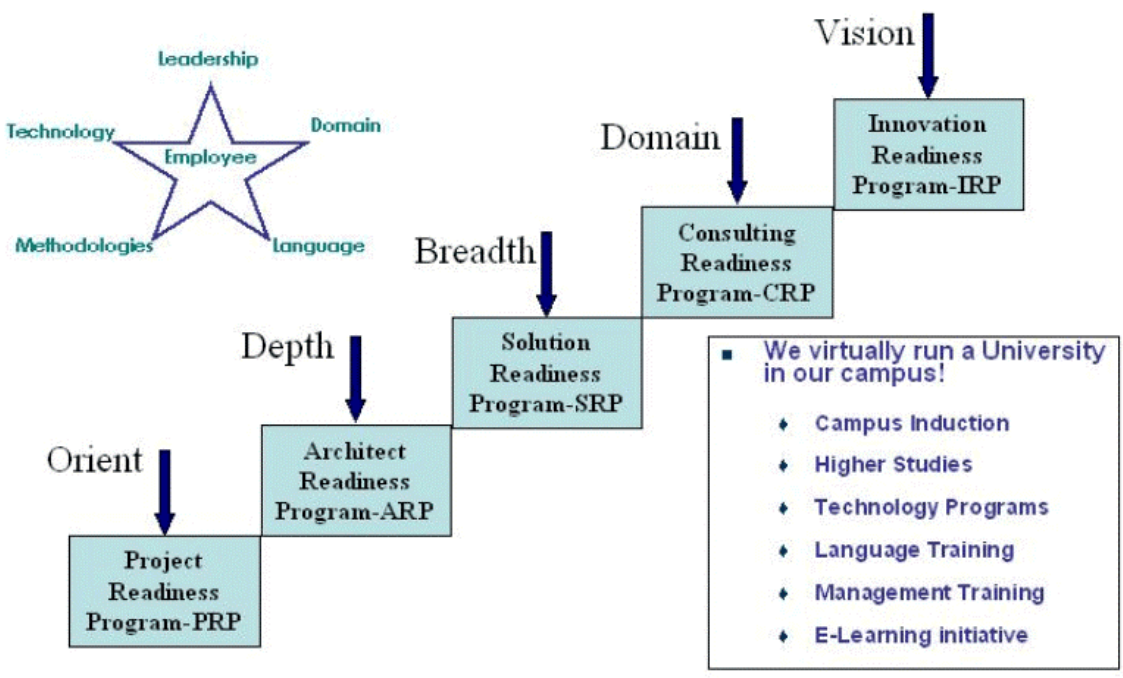

Figure 20: Talent Transformation 


\section{The Benefits}

\subsection{On-Time Delivery}

As shown in Figure 21, shifting from the "internalized approach" to "customer orientation" through the introduction of Six Sigma concepts, project-shared vision, team charter, and stressing the importance of measurement and statistics has helped Wipro improve the quality and timeliness of project deliverables and, in turn, customer satisfaction.

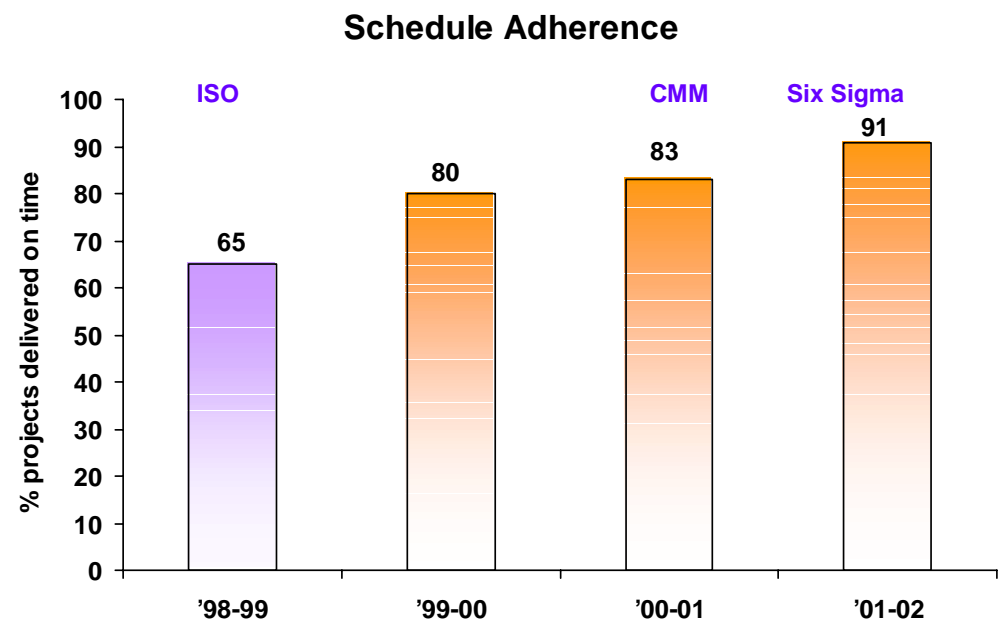

Figure 21: Schedule Adherence

\subsection{Improved Quality}

The motto of "do it right the first time," focusing on thorough and efficient verification and validation, has resulted in a significant improvement in the quality of deliverables. As shown in Figure 22, the introduction of the testing life-cycle model and enhancement to test development and testing processes have resulted in a marked decrease in field error rate (FER) and rejection indices (ratio of bug fix rejects). Further, the introduction of new tools like Voice of Customer, QFD, Pugh Matrix, and FMEA in veloci-Q helped in ensuring customer involvement throughout the SDLC, resulting in a significant improvement in product quality. 
One of the areas on which we consciously focused during the quality journey was phase containment of defects. Many process improvement initiatives that targeted phase containment of defects resulted in reduction of rework and schedule overruns over the period. With the introduction of Six Sigma methodology in software, several Six Sigma projects were undertaken to improve reviews and project management processes during the years 2000-2001. The results of these projects were incorporated in the quality system. The institutionalization of such practices has led to marked improvement in phase containment of defects, as shown in Figure 23 (between the years 2000-2001 and 2001-2002).

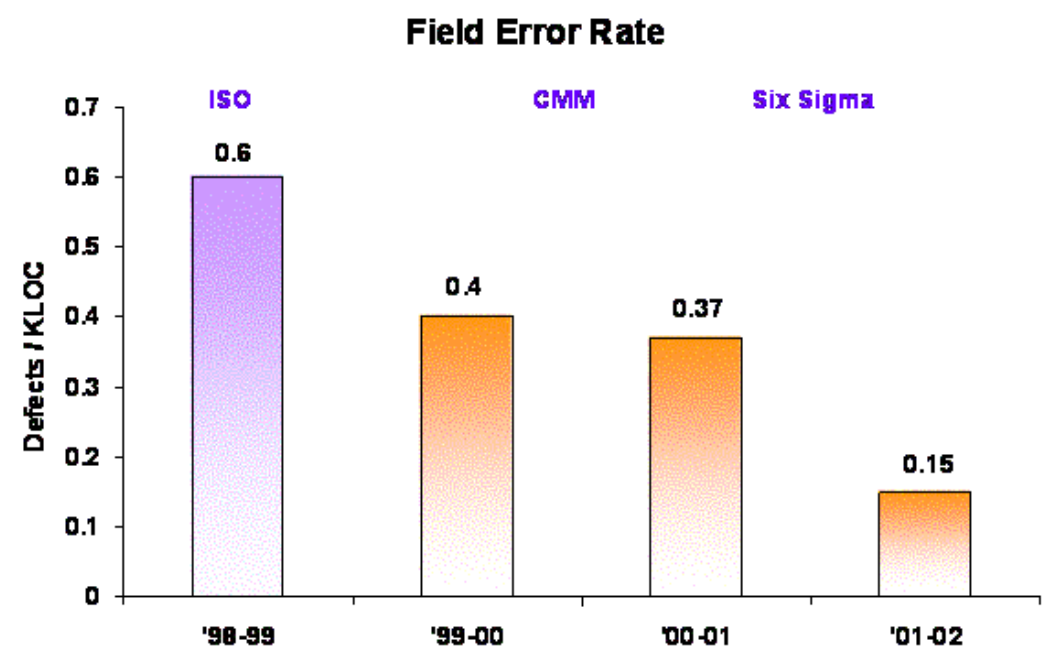

Figure 22: Field Error Rate

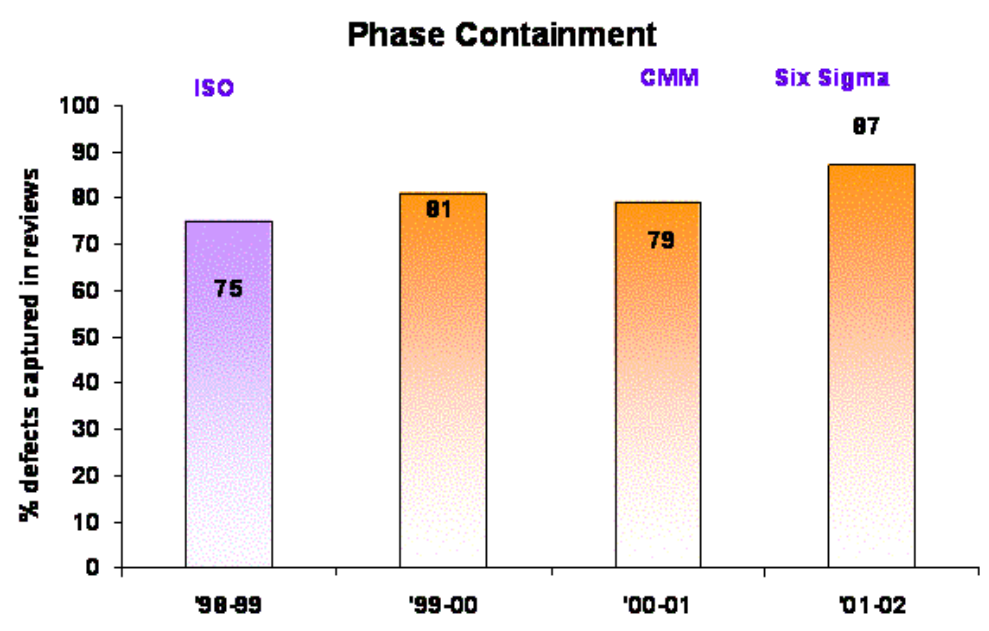

Figure 23: Phase Containment 


\subsection{For the Customers}

For our customers, this focus on excellence in quality processes has resulted in better adherence to project schedules, reduced error rates, better estimation capabilities, and minimizing the number of rejections. The net result of Wipro's total quality approach has been its ability to consistently deliver outputs to its customers on time, on budget, and in full conformance with specifications. These results are reflected in the improved customer satisfaction ratings shown in Figure 24. Customers are asked to rate us on a scale of 1 to 5 on parameters relating to delivery, quality, and service. Subsequent to our embarking on the CMM journey and adding new customers every year, we have been consistently scoring a rating of 4 and above on the overall customer satisfaction rating, as depicted in Figure 24.

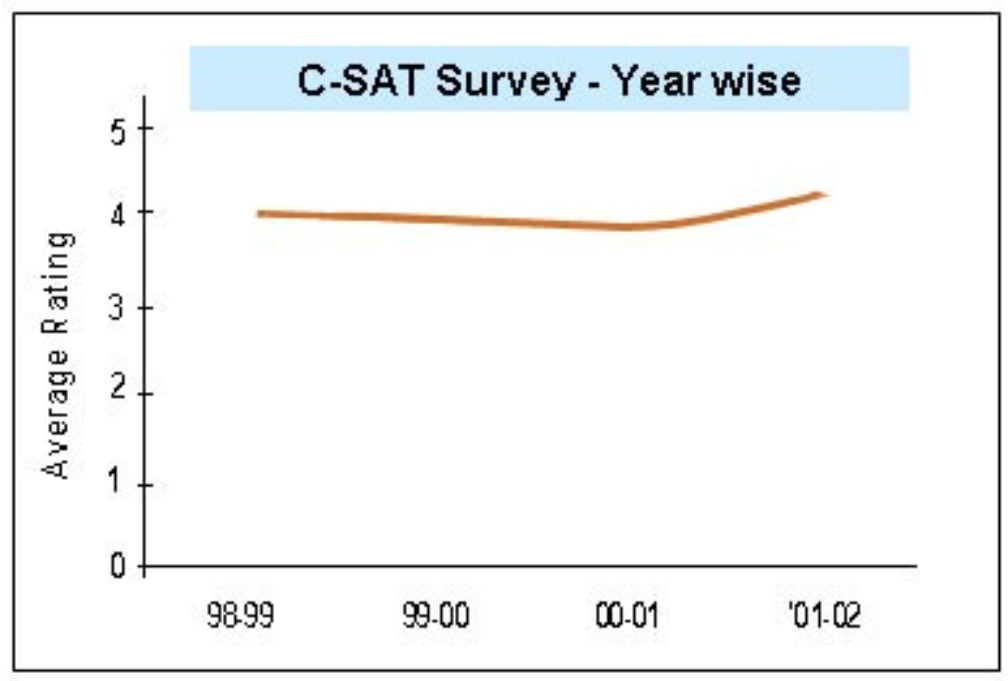

\section{Figure 24: Customer Satisfaction Survey}

Some of the perceived strengths as identified by the customers are as follows:

- good processes and tools used during the project execution

- timeliness of the deliverables

- $\quad$ skill levels and technical expertise of teams

- responsiveness to changing business needs

- flexibility in working with client

- capability to "ramp up" the team in a short time period and minimize the impact of staff turnover 


\subsection{Improvement Results}

Computing improvement results or return on investment (ROI) for a process improvement initiative is indeed a complex exercise because (1) the improvement observed (either in productivity or quality of the deliverables) is a result of several parameters, and (2) the investment made on quality has a major influence in enabling the improvement.

Analyzing the results of Wipro Technologies data over the last three years, we have observed the following overall trends:

- Productivity has improved by $40 \%$ as computed in lines of code/person-day or function points/person-week.

- Defect rate on delivered products to customers has been reduced by $60 \%$.

- Schedule adherence has improved by more than $12 \%$ (from $82 \%$ to $93 \%$ of projects being on time).

Compared to the increased investment for the three-year period we analyzed, the return accrued as a result of reduction in rework and person-effort saved as a result of productivity improvement is in the ratio of 1:2.88. The increased investment in quality is not only for maintaining the quality organization and for new initiatives, but also for investments associated with developer training, process tools for tracking metrics, effort of participation by practitioners, etc.

The improvement results computed above are in addition to the intangible but important benefits of our quality journey, which have provided the ability and capability for the organization to address the following:

- ability to adapt to varying needs of global customers

- development centers spanning multiple geographies

- requirements of a workforce of over 10,000 employees, working on diverse technology areas

- ability to provide a range of service offerings in the areas of mainframe, client server, telecom, embedded, Web-based, application, and systems integration

- a project mix including development, maintenance, testing, porting, enhancements, and other heterogeneous services

- improved personal performance at individual employee level through shorter learning curves, best practices, and experience sharing

In all, our quality initiatives have enabled us to work successfully in an integrated and vast environment as a single, uniform entity, posting sustained quarter-on-quarter business 
growth. The focus on customer-centricity and a data-driven approach to process improvement have played a pivotal role in helping Wipro Technologies to achieve its business vision and organizational goals over the past decade. Our quality initiatives have been a guiding light to such an extent that it is hard to imagine how such large-scale and diverse operations could have been managed successfully, otherwise. 
CMU/SEI-2004-TR-006 


\section{Future Focus}

The continuous measurement of benefits accrued from Wipro's process improvement initiatives has brought to light a significant reduction in rework, increase in productivity, adherence to schedules and budget, and significant added value, culminating in customer delight.

Wipro's holistic quality framework is internalized to such an extent that process improvement initiatives are undertaken with the knowledge that improvement is a continuous journey, not an end in itself. Each milestone fuels the workforce's enthusiasm and rigor towards attaining greater heights.

Wipro's primary focus will be its commitment to continuing its process optimization journey along the five key dimensions of process, organization, culture, infrastructure, and metrics. This focus will lead to the pursuit of newer dimensions of the quality management framework towards embodying a totality of process, people, product, and technology for achieving high process capability.

veloci-Q will be continuously upgraded to be aligned to current business needs, with the intent of improving software quality, increasing productivity, and decreasing cycle time for product development. Wipro will continue to analyze and incorporate industry best practices and align with international standards based on applicability and fitness for use. Infrastructure will be continuously enhanced to ensure seamless integration of people, technology, and processes. Improvement will continue to be based on a data-driven approach, with importance on using proven Six Sigma methodologies for productivity improvement, reuse building, and tools effectiveness.

In summary, the quality system will continue to be based on incremental optimization, with rigorous implementation and a strong feedback loop. 


\section{Appendix: Acronyms}

\begin{tabular}{|c|c|}
\hline ADR & American Depository Receipt \\
\hline CFPM & Cross-Functional Process Mapping \\
\hline CMM & Capability Maturity Model \\
\hline CQO & Chief Quality Officer \\
\hline CSAT & customer satisfaction \\
\hline DCAM & Designing for Customer Satisfaction and Manufacturability \\
\hline DMAIC & Define, Measure, Analyze, Improve, Control \\
\hline DNV & Det Norske Veritas \\
\hline DoE & design of experiments \\
\hline DSSS & Developing Six Sigma Software \\
\hline FAQs & frequently asked questions \\
\hline FER & field error rate \\
\hline FMEA & Failure Mode Effect Analysis \\
\hline HR & Human Resources \\
\hline IEEE & Institute of Electrical and Electronic Engineers \\
\hline IPAT & Integrated Process Automation Tool \\
\hline ISMS & Information Security Management System \\
\hline ISO & International Standards Organization \\
\hline
\end{tabular}




\begin{tabular}{|c|c|}
\hline KM & knowledge management \\
\hline KNet & Knowledge Net \\
\hline KPA & key process area \\
\hline MIS & Management Information System \\
\hline MQ & mission quality \\
\hline MR & management representative \\
\hline MRM & Management Review Meeting \\
\hline NC & non-conformance \\
\hline PCMM & People Capability Maturity Model \\
\hline PDB & Project Data Bank \\
\hline PDMR & Project Data and Metrics Report \\
\hline PIP & process improvement proposal \\
\hline PM & project manager \\
\hline PMI & Project Management Institute \\
\hline PPA & Project Performance Analysis \\
\hline PPR & Project Performance Report \\
\hline QFD & Quality Function Deployment \\
\hline QIC & Quality Improvement Council \\
\hline QMS & Quality Management System \\
\hline QSM & Quality System Manual \\
\hline$R \& D$ & research and development \\
\hline
\end{tabular}




$\begin{array}{ll}\text { ROI } & \text { return on investment } \\ \text { SDLC } & \text { Software development life cycle } \\ \text { SEE Index } & \text { Six Sigma Engagement and Effectiveness Index } \\ \text { SEI } & \text { Software Engineering Institute } \\ \text { SEPG } & \text { Software Engineering Process Group } \\ \text { SQA } & \text { software quality assurance } \\ \text { TQM } & \text { Total Quality Management } \\ \text { TQSS } & \text { Transactional Quality Using Six Sigma } \\ \text { TUI } & \text { Tools Usage Index } \\ \text { WT } & \text { Wipro Technologies }\end{array}$




\section{References}

URLs are valid as of the publication date of this document.

[CMMI 02]

[Curtis 01]

[ISO 00]

[Paulk 93]

[SCAMPI 01]
CMMI Product Team. CMMI for Systems Engineering/Software Engineering/Integrated Product and Process Development, V1.1 (CMU/SEI-2002-TR-004, ADA339221). Pittsburgh, PA: Carnegie Mellon University, Software Engineering Institute, 2002. $<$ http://www.sei.cmu.edu/publications/documents/02.reports /02tr004.html>.

Curtis, Bill; Hefley, Bill; \& Miller, Sally. People Capability Maturity Model (P-CMM), Version 2.0 (CMU/SEI-2001-MM-001, ADA 395316). Pittsburgh, PA: Carnegie Mellon University, Software Engineering Institute, 2001. <http://www.sei.cmu.edu/publications /documents/01.reports/01mm001.html>.

International Standards Organization (ISO). ISO 9001: 2000. Quality Management Systems: Requirements. Geneva, Switzerland: International Standards Organization, 2000.

Paulk, M.; Curtis, B.; Chrissis, M.; \& Weber, C. Capability Maturity Model for Software, Version.1.1 (CMU/SEI-93-TR-024, ADA 263403). Pittsburgh, PA: Carnegie Mellon University, Software Engineering Institute, 1993. http://www.sei.cmu.edu/publications /documents/93.reports/93.tr.024.html>.

Members of Assessment Method Integrated Team. Standard CMMI Appraisal Method for Process Improvement (SCAMPI), Version 1.1: Method Definition Document. (CMU/SEI-2001-HB-001, ADA 3399204). Pittsburgh, PA: Carnegie Mellon University, Software Engineering Institute, 2001. http://www.sei.cmu.edu/publications /documents/01.reports/01hb001.html>. 
CMU/SEI-2004-TR-006 


\begin{tabular}{|c|c|c|c|c|}
\hline \multicolumn{3}{|c|}{ REPORT DOCUMENTATION PAGE } & \multicolumn{2}{|c|}{$\begin{array}{l}\text { Form Approved } \\
\text { OMB No. 0704-0188 }\end{array}$} \\
\hline \multicolumn{5}{|c|}{ 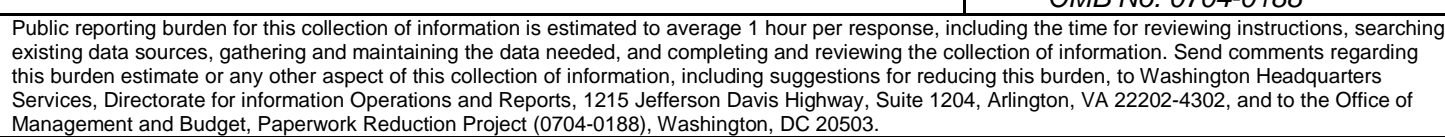 } \\
\hline $\begin{array}{l}\text { AGENCY USE ONLY } \\
\text { (Leave Blank) }\end{array}$ & \multicolumn{2}{|c|}{$\begin{array}{|ll|}\text { 2. } & \text { REPORT DATE } \\
& \text { March } 2004 \\
\end{array}$} & \multicolumn{2}{|c|}{$\begin{array}{l}\text { 3. REPORT TYPE AND DATES COVERED } \\
\text { Final }\end{array}$} \\
\hline \multicolumn{3}{|c|}{$\begin{array}{l}\text { AmLEANDSUBTTLE } \\
\text { An Integrated Approach to Software Process Improvement at Wipro } \\
\text { Technologies: veloci-Q }\end{array}$} & \multicolumn{2}{|c|}{$\begin{array}{l}\text { 5. FUNDINGNUMBERS } \\
\text { F19628-00-C-0003 }\end{array}$} \\
\hline \multicolumn{5}{|c|}{$\begin{array}{l}\text { AUTHOR(S) } \\
\text { V. Subramanyam, Sambuddha Deb, Priya Krishnaswamy, Rituparna Ghosh }\end{array}$} \\
\hline \multicolumn{3}{|c|}{$\begin{array}{l}\text { PERFORMNG ORGANZATONNAME(S) AND ADDRESS(ES) } \\
\text { Software Engineering Institute } \\
\text { Carnegie Mellon University } \\
\text { Pittsburgh, PA } 15213\end{array}$} & \multicolumn{2}{|c|}{$\begin{array}{ll}\text { 8. } & \text { PERFORMNG ORGANIZATION } \\
\text { REPORT NUMBER } \\
\text { CMU/SEI-2004-TR-006 }\end{array}$} \\
\hline \multicolumn{3}{|c|}{$\begin{array}{l}\text { 9. SPONSORING/MONTORING AGENCY NAME(S) AND ADDRESS(ES) } \\
\text { HQ ESC/XPK } \\
5 \text { Eglin Street } \\
\text { Hanscom AFB, MA 01731-2116 }\end{array}$} & \multicolumn{2}{|c|}{$\begin{array}{l}\text { 10. SPONSORING/MONTORING AGENCY } \\
\text { REPORT NUMBER } \\
\text { ESC-TR-2004-006 }\end{array}$} \\
\hline \multicolumn{5}{|c|}{ 11. SUPPLEMENTARY NOTES } \\
\hline \multicolumn{3}{|c|}{$\begin{array}{l}\text { 12A DISTRIBUTIONAVALABIUTYSTATEMENT } \\
\text { Unclassified/Unlimited, DTIC, NTIS }\end{array}$} & \multicolumn{2}{|c|}{ 12B DISTRIBUTIONCODE } \\
\hline \multirow{2}{*}{\multicolumn{5}{|c|}{$\begin{array}{l}\text { This report captures the details of Wipro's quality journey through continuous process improvement. This } \\
\text { journey towards excellence has led to the prestigious Institute of Electrical and Electronics Engineers (IEEE) } \\
\text { Computer Society Award for Software Process Achievement in 2003. This award is for achieving high soft- } \\
\text { ware process capability and establishing a basis for moving to a broad improvement program that concerns } \\
\text { people and products, rather than just the processes. } \\
\text { This report details the process improvement activities and the evolution of processes and systems over a pe- } \\
\text { riod of time. Wipro's integrated approach to quality - veloci-Q—is detailed with an emphasis on the process } \\
\text { improvement initiatives, supporting technology, and people capability that bring positive business results and } \\
\text { enable Wipro to meet its customers' ever-increasing demands. The challenges and benefits accrued from } \\
\text { Wipro's total quality approach are outlined, including the quantitative results of measuring the impact of } \\
\text { Wipro's process improvement model. }\end{array}$}} \\
\hline & & & & \\
\hline \multicolumn{3}{|c|}{$\begin{array}{l}\text { 14. SUBJECT TERMS } \\
\text { process improvement, processes, systems, quality, process } \\
\text { management, Capability Maturity Model Integration, Software Process } \\
\text { Achievement }\end{array}$} & \multicolumn{2}{|c|}{$\begin{array}{l}\text { 15. NUMBEROF PAGES } \\
73\end{array}$} \\
\hline \multicolumn{5}{|l|}{ 16. PRICECODE } \\
\hline $\begin{array}{l}\text { 17. SECURTY CLASSIFCATION } \\
\text { OF REPORT } \\
\text { Unclassified }\end{array}$ & $\begin{array}{l}\text { 18. SECURTYY CASSIFCATION OF } \\
\text { THSPAGE } \\
\text { Unclassified }\end{array}$ & $\begin{array}{l}\text { 19. SECURTY CLAS } \\
\text { ABSTRACT } \\
\text { Unclassified }\end{array}$ & SIFCATION OF & $\begin{array}{l}\text { 20. LMTATION OF ABSTRACT } \\
\text { UL }\end{array}$ \\
\hline
\end{tabular}

